Article

\title{
Goal-Driven or Data-Driven? Inventory of Sustainability Indicator Initiatives in Rural Canada
}

\author{
Brennan Lowery ${ }^{1, * \mathbb{C}}$, John Dagevos ${ }^{2} \mathbb{D}$ and Kelly Vodden ${ }^{3}$ \\ 1 Interdisciplinary PhD Candidate, Memorial University of Newfoundland, St. John's, NL A1C5S7, Canada \\ 2 Telos, Tilburg School of Economics and Management, Tilburg University, 5000 LE Tilburg, The Netherlands; \\ J.F.L.M.M.Dagevos@tilburguniversity.edu \\ 3 Environmental Policy Institute, Grenfell Campus, Memorial University of Newfoundland, \\ Corner Brook, NL A2H5G4, Canada; kvodden@grenfell.mun.ca \\ * Correspondence: bclowery@mun.ca
}

Received: 14 September 2020; Accepted: 13 October 2020; Published: 16 October 2020

check for updates

\begin{abstract}
This article seeks to address knowledge gaps on sustainability indicators (SIs) in rural and natural resource-dependent communities, considering how they are used to contextualize sustainable development priorities and support local governance. We build on recent scholarship on the potentials of SIs for stimulating societal transformation, extending this inquiry into rural and resource-based communities which have been under-represented in SI research. The governance challenges facing rural Canada, as well as its geographic and socio-economic diversity, provide a unique context for examining these issues. We provide relatively uncommon synthetic findings by compiling an inventory of SI initiatives across 39 rural communities and regions of Canada. Using the Community Capital Framework, we examine grey literature and academic publications related to each initiative spanning from 1999-2019 to determine the breadth of sustainable development priorities considered. Informed by collaborative and multi-level governance frameworks, we explore how these initiatives are used to support multi-stakeholder collective action. This article finds that rural Canadian SI initiatives prioritize socio-cultural capital, with relatively fewer economic and ecological indicators, while identifying a typology of SI use and inter-related governance dynamics informing how these priorities and indicators are determined. Although some initiatives display highly collaborative and bottom-up processes, many rural Canadian SI initiatives are characterized by a data-driven approach that, when met with local capacity gaps, fails to contextualize standardized datasets to reflect rural realities. We encourage more in-depth investigation of these findings and comparison of Canadian experiences to other jurisdictions.
\end{abstract}

Keywords: sustainability indicators; sustainable development; rural development; Canada; collaborative governance; regional development

\section{Introduction}

Communities and regions worldwide have used indicators to monitor progress towards sustainable development (SD). Popularized by global calls to action such as Agenda 21 [1], and more recently the Sustainable Development Goals (SDGs) [2], sustainability indicators (SIs) have been articulated at local, national, and international scales [3]. However, SI research tends to focus on urban contexts [4,5], with relatively few studies in rural and natural resource-dependent areas. Recent entries in Sustainability have called for wider contextual variety in SI research and practice [6,7], which is needed to assess the unique sustainability conditions of rural areas [8], while also reflecting global priorities like climate action and gender equity. The multi-dimensional goals of protecting natural capital while enhancing 
social equity and economic prosperity reveal conflicting stakeholder interests that must be addressed in pursuit of a holistic SD agenda [9,10].

Researchers debate how stakeholders should use SIs to support sustainability transitions and influence governance at local, national, and global scales [11-14]. Some have contended that SIs must be adopted by policy-makers in an instrumental fashion to have tangible impact [15,16]; others argue that they should play more indirect roles like facilitating multi-stakeholder dialogue $[11,17,18]$. These debates relate to alternative perspectives on governance that highlight the complexity of sustainability challenges and call for collaboration between state and non-state actors at multiple scales [19-21]. SI tools may complement these collaborative governance arrangements when approached through a participatory process $[4,22]$. However, it is unclear how local stakeholders can use SI tools to support such efforts in rural contexts.

Rural Canada has experienced government retrenchment resulting from neoliberal policy agendas, leading many communities to explore regional collaboration as a strategy for addressing sustainability challenges [23,24]. Several tools have been developed at national, provincial/territorial, and local levels to measure well-being and sustainability [25-27], including SI case studies in rural areas [28-30]. However, to our knowledge no research has integrated insights from individual cases to understand if and how rural Canadian communities and regions have employed SIs, and whether these tools have aided rural stakeholders in responding to local governance challenges.

The primary goal of this article is to address these gaps by synthesizing knowledge of existing efforts to apply SIs in rural Canada, illuminating patterns across individual SI experiences and informing future use of these tools in rural contexts. We ask the following research questions:

1. Do SI tools in rural and resource-dependent Canadian communities and regions portray a holistic SD vision?

2. Do these initiatives support local governance in rural communities and regions, and if so, how?

To answer these questions, the article compiles an inventory of SI initiatives across rural Canadian communities and regions. We begin by outlining a holistic SD vision based in the Community Capital Framework (CCF) $[10,31]$, considering that it can be defined and operationalized in various ways (see Section 1.1), and describing how SIs have been used to advance this vision. We also discuss the knowledge gap around SI use in light of governance challenges facing rural Canada. Next, we outline the methods used to examine publicly available documents, including grey literature and academic publications spanning from 1999-2019, on 39 SI initiatives in rural and resource-based areas of Canada, using qualitative and descriptive quantitative tools to describe their characteristics and to what extent they reflect a holistic SD vision. Finally, we examine the role these initiatives are intended to play (and in some cases have played) in local governance, assessing various actors involved and to what extent they reflect collaborative and multi-level governance characteristics $[19,20]$, and presenting a typology of rural SI use and related governance dynamics to inform future research.

\subsection{Need for a Holistic SD Vision}

In rural and urban communities alike, SD occurs at the nexus of interconnected social, economic, ecological, and political systems [32,33]. This calls for a holistic approach to local development that considers multiple forms of capital, primarily to halt unchecked economic growth at the expense of ecosystems $[34,35]$. From a strong sustainability perspective, ecological capital has inherent value and should not be substituted by produced assets, implying a non-declining stock over time (in contrast to weak sustainability, in which natural capital can be degraded as long as the total capital stock remains stable or grows) [36]. Social capital is crucial for maintaining bonds of trust between individuals and groups through both formal and informal networks and promoting equity $[37,38]$. Human capital has long been acknowledged as an essential development priority, recognizing the importance of a healthy and educated population for economic productivity [39]. Finally, cultural capital informs societal conceptions of sustainability and highlights the importance of diverse and inclusive societies [32,40]. 
This community capital-based approach can be applied in a flexible manner to operationalize local SD priorities. Some articulations of the CCF identify up to seven forms of capital, assessing cultural, political, human, or physical capital independently [41]. However, based on the three-legged stool approach to SD popularized by Serageldin [9] and others, the CCF can also be arranged into ecological, economic, and socio-cultural capital, while reflecting the strong sustainability perspective to ensure that ecological integrity is not sacrificed for advances in other capitals [42,43]. These forms of capital must be operationalized into local context by identifying their various sub-systems, or stocks, which are informed by the interdisciplinary research foundations of the CCF and local priorities. For example, natural capital may include stocks like ecosystems, soil, ground and surface water, air and climate, minerals, and landscape [42]. In this systems-based approach, the CCF envisions SD as a process that requires short-term trade-offs but builds on the interconnectedness between capitals and stocks to prioritize holistic development in the long-term [10,44]. This three-capital model of the CCF is portrayed in Figure 1, including a sample set of stocks.

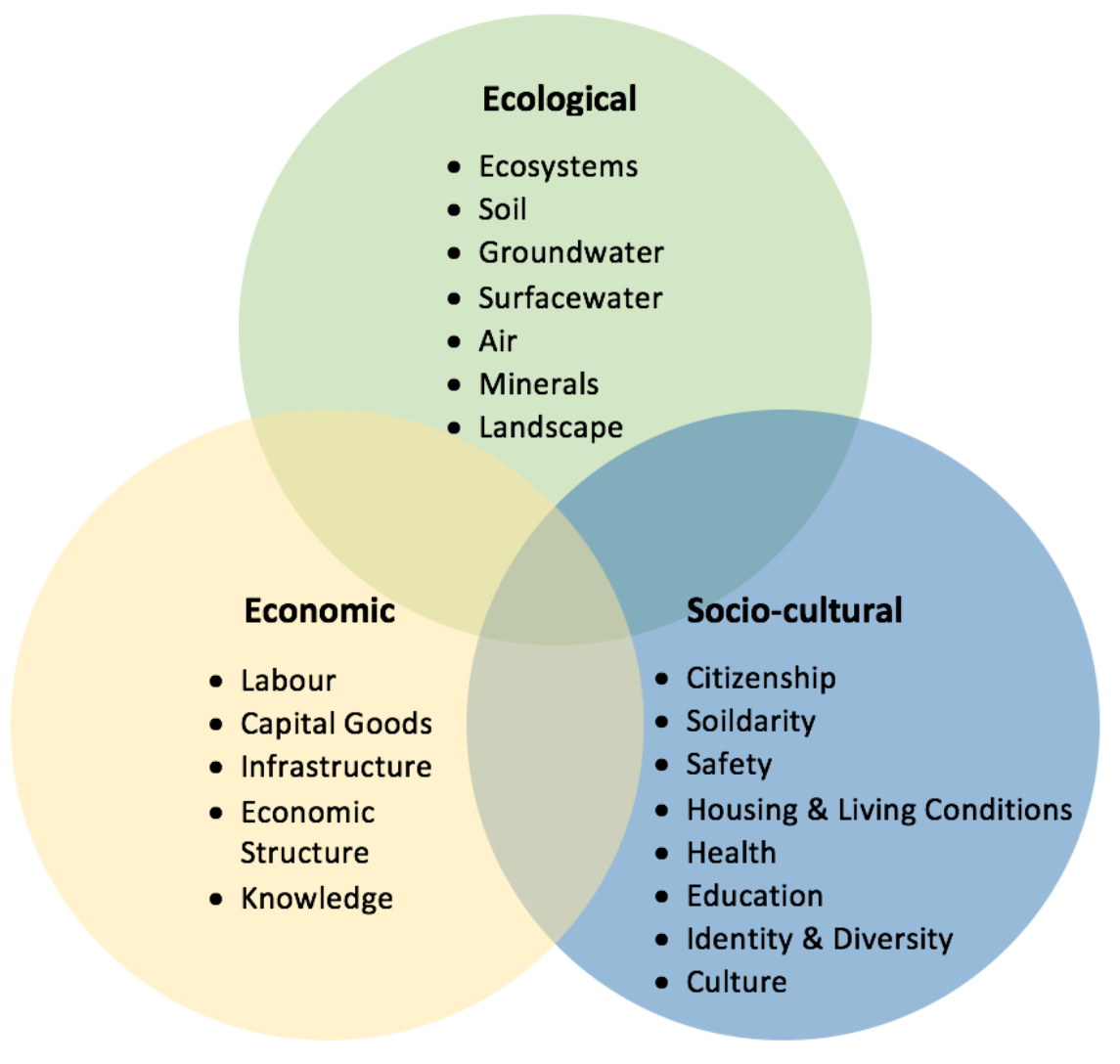

Figure 1. Three-capital model of the Community Capital Framework (CCF) with sample stocks. Adapted from Knippenberg et al. (note that these provide a basic framework to inform the identification of stocks at the local level, not a standard set of stocks that must be applied in all cases). See Section 2.4 for the process used to adapt this framework to reflect the most salient stocks across rural Canadian SI initiatives.

The CCF has been widely used for understanding sustainable community development (SCD). For example, Bebbington [45] examined sustainable livelihoods in Andean villages, contending that their unique capabilities could be harnessed to resist their labelling as 'non-viable' under neoliberal policy agendas. Emery and Flora [46] discuss how the CCF aided rural Nebraska communities in "identifying community capitals and strategically increasing capitals stocks" (p. 19). As mentioned above, these stocks and the specific sustainability goals linked to them must reflect key sustainability 
challenges in the local system while considering stakeholder perspectives [41]. The CCF has been used in numerous contexts, from evaluating the sustainability of Dutch cities [44] to forest community resilience in rural Mexico [47], and numerous other locales [30,48-51].

\subsection{Using Local Indicators in Collaborative Governance for $S D$}

This holistic approach often reveals conflicting development priorities that require a collaborative process to create mutual understanding and shared goals among diverse stakeholders [33,52]. Governance frameworks call for multi-sectoral collaboration [20,53], in which civil society, business, and local authorities work alongside upper-level governments in novel power-sharing arrangements $[19,54]$. This collaborative governance approach engages local residents meaningfully in co-designing decisions that affect them, rather than shallow forms of participation like tokenism or consultation [55], while striving for genuine collaboration that requires actors to devote time, develop trust, and relinquish some control over jurisdictional authority [56]. Compared to conventional statist governance, this approach is considered more appropriate for addressing sustainability challenges that are complex in nature, embedded in dynamic socio-ecological systems, and affect diverse stakeholder groups $[21,23,53]$.

The need to balance diverse stakeholder interests (and differing priorities across community capital areas) requires a common understanding of what SCD means in context and tools for determining whether communities are moving towards it over time. International frameworks from Agenda 21 to the SDGs have called for sustainability indicator (SI) frameworks to guide communities towards SD [1,2], for which countless tools have been developed [6]. Academic SI frameworks originated in expert-driven tools $[57,58]$, but have increasingly emphasized stakeholder participation and local perspectives [12,59]. Many local SIs have also encouraged social learning among diverse stakeholders through shared reflection and visioning $[17,60]$.

Nevertheless, researchers and practitioners continue to debate how SIs should be used in governance. Some have argued that indicators must be directly incorporated into formal, government-driven policy and planning decisions to influence SD outcomes [15,16,61]; others have broadened the focus beyond government actors by calling for multi-stakeholder engagement and transparency in indicator design [11,12,22,62]. Distinct uses of SIs have been delineated, namely instrumental use as direct policy inputs versus conceptual use in informing multi-stakeholder dialogue, which may in turn influence behaviors or policy and planning decisions over time [16]. The former has been observed in cases like Portuguese municipalities that have embedded SIs into sustainability planning guided by European Union frameworks [13], and Dutch jurisdictions that have used a community capital-based process called the Sustainability Balance to monitor regional sustainability [42,44]. However, this direct policy use is rare in practice [18], and even when this occurs it is difficult to measure the ultimate impacts on SD outcomes. In a recent meta-analysis, Ramos [6] identified ongoing knowledge gaps in institutionalizing SIs into governance and understanding how they may be used differently across community or cultural contexts.

Instead, Holman [12] suggests that SIs are more commonly linked to facilitating multi-stakeholder discourse and encouraging shared understanding. SIs have often aided local actors in translating global imperatives like Agenda 21 into context-specific SD goals with significant citizen participation $[4,17]$. Therein, indicators can 'strike a chord' with different audiences [16], providing local stakeholders with a "common language to talk about sustainable development" [22]. Nonetheless, this evidence of 'soft impacts' has not clarified whether these participatory approaches lead to tangible SD outcomes [3,17]. One challenge is the complex nature of societal transitions towards sustainability, which confront vested interests with a stake in preserving the status quo [63], and take considerable time to develop a shared vision among diverse stakeholders [53,55]. Bell and Morse [3] call for meta-analytical work to integrate knowledge of SI use experiences and examine how they are formulated by various stakeholders, a call to which this article responds. 


\subsection{Under-Representation of Rural SI Tools}

Furthermore, SI tools tend to be developed and applied in urban contexts, with relatively few examples from rural communities and regions. Although some case studies have examined rural areas $[45,46]$, research in urban settings is much more common $[6,13,64]$. Recent studies have expanded the focus into areas like Arctic cities and remote regions [7,65], and Indigenous contexts such as the Maori [62]. However, a scan of recent literature reveals that, out of 87 worldwide SI case studies, only 22 focused on rural settings (25\%), compared to 52 urban case studies and 13 focusing on regions including both urban and rural communities (which mostly included rural areas as part of a larger metropolitan area). We searched the Scopus database for the following keywords: "sustainability indicators", "local", and "communit", limiting the search to peer-reviewed articles and book chapters published between 2011-2020. This gap widens in North America, where only two studies were retrieved with a rural focus ( $9 \%$ of rural case studies).

Although rural communities are generally under-represented in indicator-based research, extant studies in non-metropolitan contexts have often examined communities that depend on natural resource industries (which describes many, although not all, rural communities). For example, forestry-dependent Canadian communities have been the subject of both academic SIs and federal forestry policies $[28,66]$, while community-based fisheries monitoring has complemented and even challenged official stock assessments [67]. The mining sector has responded to criticism by undertaking corporate social responsibility reporting efforts and entering into Impact and Benefit Agreements [68,69], with adjacent communities using SIs to anticipate the impacts of mining activity [30]. In these contexts, SIs may act as early warning signals for communities whose dependence on a single industry leaves them vulnerable to ecological and economic shocks [58]. However, such research rarely spans across natural resource sectors (e.g., comparing indicators of forestry-based and mining communities), or considers sustainability challenges facing rural communities that do not rely on natural resource extraction.

\subsection{The Rural Canadian Context}

Canada features diverse geographic, economic, and demographic conditions in rural and natural resource-based places [70]. Rural Canada also faces considerable governance challenges stemming from the withdrawal of upper-level government support, forcing local actors to explore alternative governance arrangements based in cross-community and sectoral collaboration [24]. There is also a variety of SI tools at various levels that rural stakeholders may be able to adapt $[25,26]$.

\subsubsection{Diversity of Rural Geographies}

Rurality is a socially constructed and context-dependent concept [71], with the only commonly agreed-upon factors being low population density and distance from high-density settlements [72], which vary across national and regional scales. It is also shaped by rural citizens' subjective experiences and attachments to place [73], as well as identities imposed by urban residents onto rural people [74]. In Canada, quantitative benchmarks exist like the 'Census rural' designation (including all residents outside of communities of 1000 or more with a population density below 400 inhabitants per $\mathrm{km}^{2}$ ), or the 'rural and small town' (RST) designation which also includes communities beyond population centers of 10,000 or more [75]. However, many communities that fall outside of these thresholds may be considered rural in their regional contexts or have histories of resource dependence linking them to rural regions through manufacturing activities like pulp and paper production or agri-foods. Depending on the definition used, Rural Canada comprises between $17-19 \%$ of the overall population (6-6.5 million residents) [76,77].

Rural Canada experiences considerable diversity across these criteria. Approximately $2 / 3$ of Canada's population lives on only $4 \%$ of the country's landmass along the southern border, creating geographic disparities between southern and northern regions $[8,78]$. Northern residents predominantly live in rural and remote communities, with few cities above 100,000 residents (the cut-off for Census 
metropolitan areas, or CMAs), although what constitutes a Northern or remote community varies across provinces (with Canada's three territories all in the North). Canada's North is also largely populated by Indigenous Peoples, who were often forced into permanent settlements from nomadic lifestyles by colonial policies [79]. In contrast, more southerly rural communities are often highly interdependent with nearby cities, linked by regional sustainability issues like food systems [80] and labor markets [81]. Some rural areas have become sought-after destinations for urbanites seeking amenities like low-cost housing and the therapeutic and recreational benefits often associated with rural landscapes [82-84]. In contrast, remote communities are often connected to urban centers only through natural resource extraction activities [85]—in which companies with largely urban headquarters extract resources from remote regions-and policies set by decision-makers in urban-based government institutions.

\subsubsection{Shifting Role of Natural Resource Economies}

Canada's history has been shaped by primary resource extraction, from early European mercantilist colonization to subsequent nation-building and resource-based development policies [85,86]. Although primary industries have gradually declined in national economic importance, and in many rural communities, they remain important economic generators. In 2018, natural resources contributed $11.3 \%$ to Canada's gross domestic product, with the fossil fuel-based energy sector contributing $7.6 \%$, mining 2.4\%, and renewable resources (i.e., agriculture, forestry, fishing, and hunting) $1.3 \%$ [87]. Natural resources constitute $49 \%$ of national export revenue [88], and contribute heavily to government revenues in many jurisdictions.

Natural resources are also important at the local level, with over 900 Canadian communities directly depending on at least one resource sector [88]. Across Canada's over 1800 rural and remote communities (the majority having fewer than 10,000 inhabitants), $30 \%$ on average of labor force income is derived from natural resource-based activities [89], and recent data show that $11 \%$ of the workforce in RST areas is employed in these sectors [90]. (Statistics Canada divides resource-based occupations into two categories: 1) agriculture, forestry, fishing, and hunting; and 2) mining, quarrying, and oil and gas extraction). Nonetheless, primary sector employment has declined in many areas due to overharvesting, automation, global competition, and other factors. Resource-based communities could lose more jobs due to automation, with many communities that depend on natural resources and manufacturing at high risk of having local jobs automated out of existence [91].

\subsubsection{Uneven Demographic Landscape}

Demography reflects several important factors of community sustainability. Firstly, the retention (or attraction) of youth and young families in rural communities indicates that entrants to the workforce see opportunity in the local labor market, while the working population is generating tax revenue to sustain local services [92]. Conversely, a high proportion of retirees suggests that the economically productive population is dwindling, creating an imbalance between tax-generating economic activities and rising demands for services like healthcare and housing. Thirdly, in-migration of urbanites could be linked to an appealing set of local amenities [93]. while the influx of immigrants may suggest that there is a range of services for welcoming, settling, and retaining newcomers [72], but may also reveal local labor shortages and can be linked to the discrimination of visible minorities.

Like most industrialized countries, Canada's population has gradually urbanized, with the rural population (according to the Census rural definition) shrinking from $87 \%$ in 1851 to $19 \%$ in 2016 [94,95]. Nonetheless, the rural population grew by $1.5 \%$ between $2011-2016$, but at a slower rate than cities (6\%) [76]. These demographic trends vary considerably across provinces and regions. For example, between 2011-2016 the rural population of Atlantic provinces declined by between 2-3\% [96], while rural Alberta's population grew by $4 \%$ [76]. 


\subsubsection{The Need for Collaborative Approaches to Rural Governance}

Rural Canadian communities are adapting to the retrenchment of upper-level government support. Beginning in the 1980s, cutbacks to the welfare state meant that services to rural populations were often the first to be reduced [86]. Furthermore, rural policy often takes a sectoral approach, rather than following a holistic agenda [70]. For example, rural development in Ontario is the mandate of the Ministry of Agriculture, Food, and Rural Affairs, while in Newfoundland and Labrador (NL) it fell under the tourism ministry until 2016, when the word 'rural' disappeared from the department's title [97-99]. After the federal Rural Secretariat was dismantled in 2013 [100], there was no coherent national policy until a new rural economic development strategy and ministry was announced in 2019 [101].

In the face of retracting senior government support, many rural communities have strengthened local governance capacity through collaborative approaches [8]. Although Canada has no uniform level of government between municipal and provincial/territorial levels, rural communities are increasingly working at the sub-provincial regional scale to share services through cross-community and sectoral collaboration [86]. Regional approaches allow rural communities to pool resources to enhance often-limited municipal capacity [102], while providing an appropriate scale to address issues like water management and economic development $[24,103,104]$. In some provinces, these efforts are supported by regional government structures like BC's regional districts and Québec's municipalités régionales de comté [86]. In contrast, NL has experienced the dismantling of rural development institutions that once provided key regional capacity to small municipalities [98].

Within collaborative regional approaches, a critical question is how rural Canadian communities can engage with Indigenous Peoples (First Nations, Inuit, and Métis) in a mutually respectful manner. Given the current agenda for reconciliation between Canada and the Indigenous Peoples who lived there before colonization (and into current times), including federal commitments following the Truth and Reconciliation Commission [105], rural regions can be important sites for collaboration and knowledge-sharing between Indigenous nations and nearby communities [106]. These efforts must acknowledge that Indigenous Peoples have their own unique rights, responsibilities, and ways of knowing, which have informed a number of indicator-based tools [107-109]. Since these SI projects are informed by an entirely different worldview from those stemming from Western science and policy, the ways in which Indigenous Peoples define and measure sustainability must be considered.

\subsubsection{Canadian SI Tools}

Several indicator-based tools have been developed in Canada at various scales that may inform local efforts in rural areas. The Canadian Index of Well-being (CIW) provides an alternative measure of national welfare [26], including applications at provincial and local levels [110]. Another platform is Vital Signs, coordinated by a national non-profit organization that supports community foundations across the country in developing local indicator reports on quality of life and SD [25]. The federal government's environmental assessment process, which involves the analysis of ecological and socio-cultural indicators to evaluate major development projects, was revised in 2018 [111]. The Genuine Progress Indicator, an alternative to Gross Domestic Product with numerous applications at national and state/provincial levels, has been advanced by its use in Nova Scotia and Alberta [112]. At the provincial level, also, the System of Community Accounts was introduced in NL to make official data more accessible to the public, allowing for retrieval of data at various aggregation levels [113]. At the community and regional scale, which is the focus of this article, several SI case studies have been also conducted in rural areas [28-30,107,109]. However, echoing Bell and Morse's critique of the case study-dominated SI field [3], to our knowledge no research has looked across individual rural Canadian SI experiences to compare their design and use at the local level. Furthermore, considering the governance challenges facing rural Canada and interest in collaborative approaches, there is a need to understand whether, and how, SIs can support collaborative arrangements in rural regions. 


\section{Materials and Methods}

This study compiled an inventory of rural SI initiatives based on available secondary information, drawing from both grey literature and academic publications. Its methods were informed by qualitative meta-synthesis, a systematic form of interpretivist research that seeks not to aggregate existing findings through deductive statistical procedures (as with quantitative meta-analysis), but contribute to research by illuminating patterns and proposing new directions $[114,115]$. We also draw from quantitative research synthesis tools such as case surveys [116].

\subsection{Identifying Rural SI Initiatives}

We began by identifying a broad array of rural Canadian SI initiatives. Using purposive sampling, this process intended not to exhaustively identify all SI initiatives in rural Canada, but represent a diversity of rural contexts and approaches to indicator development and use. Intentionally excluding initiatives at the provincial/territorial scale, we focused on the community and sub-provincial regional level while considering how these local initiatives linked to higher-level frameworks. We began by searching scholarly databases, but after noting few studies on rural Canadian SI initiatives in available academic research (see Section 1.3), we also consulted non-academic resources like Vital Signs (https://www.communityfoundations.ca/vitalsigns/reports/) and the Community Indicators Consortium (https://communityindicators.net/), locating grey literature such as project reports and websites. Case study documents were located in English, using keywords like "sustainability indicators", "rural", "well-being", "monitoring", and "Canada". We searched for documents dated between 1999-2019, but since many initiatives had produced multiple documents (e.g., updated indicator reports), we examined the most recently produced document in-depth for each project. Limited French abilities among the research team prevented in-depth investigation of materials from Francophone areas (e.g., Québec); a provincial SD indicator system was found [117], but no local iterations of this framework were identified.

To classify the rurality of each initiative, we were informed by the RST classification (see Section 1.4), but applied it in a flexible manner considering the variability in conceptions of rural identity across provinces and regions. This process consisted of identifying whether a given initiative fell within an RST area, a census agglomeration (CA, or smaller population center between 10,000-100,000 residents), or was on the fringes of a CMA, while simultaneously assessing whether project documents self-described the community or region as rural. We also considered small cities (population $<100,000$ ) which either depended historically or presently on natural resource sectors and were not adjacent to a CMA. We initially identified 56 initiatives in seven of Canada's ten provinces (no initiatives found in the territories). Of these, 39 were Vital Signs initiatives (69\%), two were derivations of the CIW, and the remaining 15 were not affiliated with any national SI tool.

\subsection{Exclusion Criteria}

Next, we applied several exclusion criteria to refine the initially identified set of rural SI initiatives. The first goal of this process was to reduce the number of cases in the sample to allow for more in-depth analysis of each case, while still following a meta-synthetic approach that prioritized breadth over depth. Informed by the rural contextual factors discussed in Section 1.4, we sought to limit the sample to a set of initiatives that represented a diversity of rural geographies (e.g., small city, urban-adjacent, and remote), regional economic structures (including both highly natural resource-dependent areas and ones without significant resource activity), and demographic trends (growing vs. declining). Thus, initiatives in communities or regions that overlapped geographically or were heavily concentrated in one region (e.g., southwestern Ontario, coastal British Columbia) were excluded to avoid over-representation of one context, while still including at least one from the same area. We included regions located partially in a metropolitan area to represent communities on the urban fringe (e.g., Selkirk, MB), but excluded regions that included an entire CMA (e.g., Kelowna, $\mathrm{BC}$ ), since this scale would be more appropriately 
considered a metropolitan region. We also sought to represent SI initiatives developed by Indigenous Peoples in reserves or upon their traditional territories, and initiatives occurring in Northern or remote communities (which often overlap).

The exclusion process was also informed by the consideration of geographical scale, both to identify at what level rural SI initiatives are most commonly conducted and how scale relates to local governance factors. We sought to include both initiatives in formal administrative regions (e.g., municipality, county) and in areas not based on formal boundaries (see Section 3.3). This process ensured that the sample included initiatives at both the single community and regional scale, representing a variety of ways that regional scope can be defined. Simultaneously, we wanted to ensure that all initiatives focused on sustainability at the community or regional level, rather than taking a sectoral or issue-based focus. Thus, we excluded initiatives that focused on a single topic (e.g., agriculture, forestry, schools), since these initiatives would not likely be comparable to others that considered a wide range of local issues.

Based on these criteria, we excluded 17 initially identified cases, including 12 Vital Signs and five grassroots initiatives; of these, seven initiatives were in Ontario, five in BC, three in Alberta, and one each in NL and Nova Scotia. (See supplementary material for a list of excluded initiatives and their locations). Most excluded initiatives were geographically close to a project that was included for further analysis, meaning that the geographic distribution of all identified cases was similar to those represented in the selected cases (Figure 2). Of the 39 remaining, 15 (38.5\%) were in BC, 10 in Ontario $(25.6 \%)$, six in Nova Scotia (15.4\%), three each in Alberta and Manitoba $(7.7 \%)$, and one each in Québec and NL. As shown below, most were located in southern Canada, with only three located in self-identified northern regions. Twenty-seven (69.2\%) were Vital Signs initiatives, 10 (25.6\%) grassroots, and two (5.1\%) CIW.

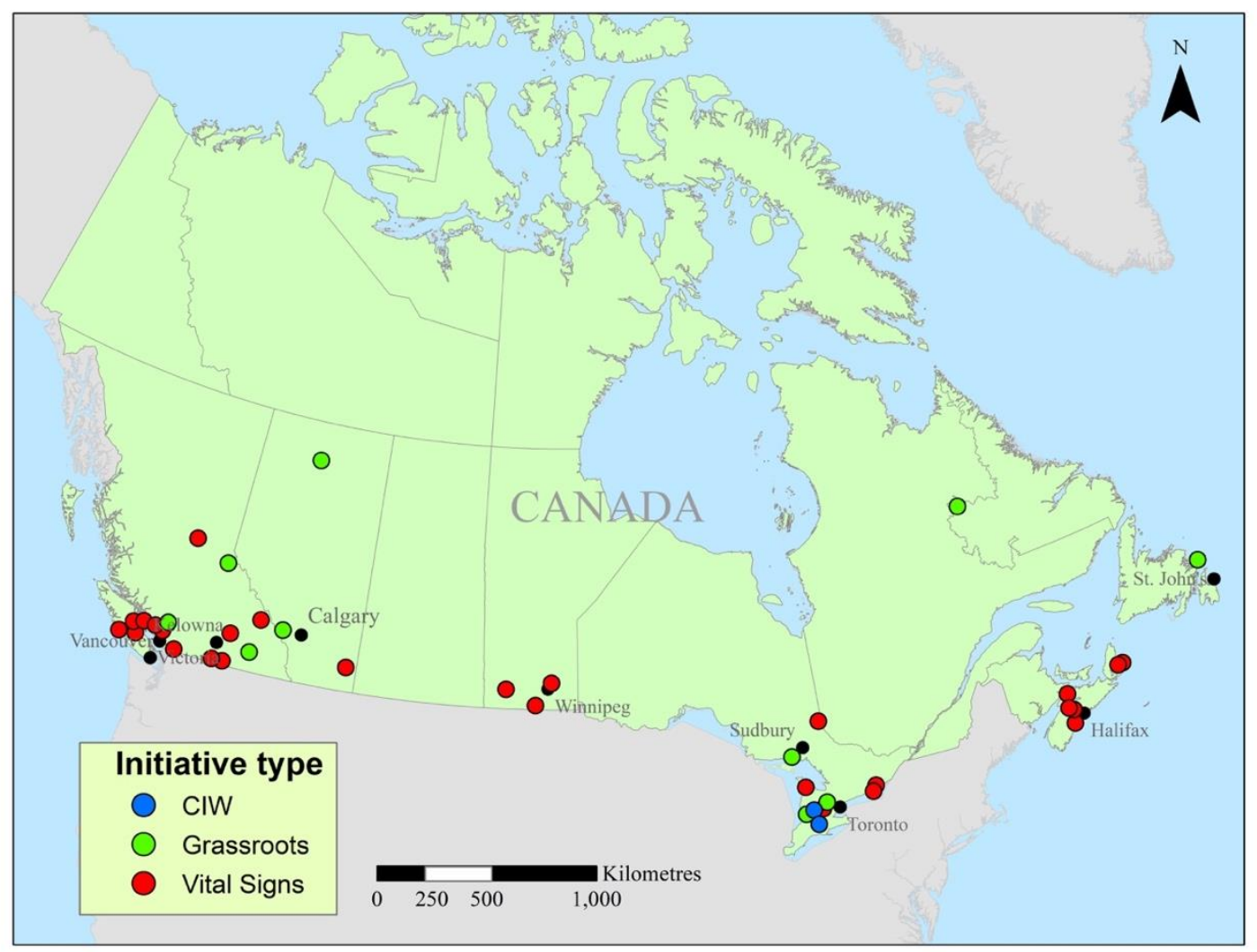

Figure 2. Map of rural Canadian SI initiatives included in the inventory. (Map prepared by Myron King, Environmental Policy Institute, Grenfell Campus of Memorial University). 


\subsection{Comparing Community and Initiative Characteristics}

Next, to better understand the rural contexts in which the SI initiatives occurred, we compiled descriptive quantitative trends, including: demographic factors (i.e., population size, rate of growth/decline); major employment sectors, including the proportion of natural resource occupations; and, using Statistics Canada classifications to identify the nearest CMA, level of rurality. Based on thresholds identified by Freshwater et al. [81], who used commuting distances of $100 \mathrm{~km}$ or less to define functional economic regions in Atlantic Canada, and considering regional variations in factors like road quality and topography (which can greatly affect transportation conditions), we classified all communities within $150 \mathrm{~km}$ of a CMA urban-adjacent, those over $150 \mathrm{~km}$ as non-urban adjacent, and noted areas which self-identified their community or region as Northern and/or remote (which is conceived differently across provinces).

\subsection{Community Capital Analysis}

To assess whether these initiatives represented a holistic SD agenda, we used the CCF [31,45], approaching the indicators used in each SI initiative as a set of stated sustainability priorities and examining how they reflected different forms of community capital. This assessment used a three-capital model informed by the three-legged stool concept [9], starting with a basic set of stocks (see Figure 1), but adapting them considerably to fit salient SD priorities described in project documents. We drew from the Sustainability Balance approach, which offers tools for operationalizing SCD by linking capitals, stocks, and indicators [42,44]. Figure 3 shows how this method uses aggregation and data visualization tools to score all indicators related to a given stock, with each indicator's score contributing to the overall status of each stock and capital (represented by the smaller triangle that shows each capital's performance in relation to an ideal state).

\section{The Telos triangle}

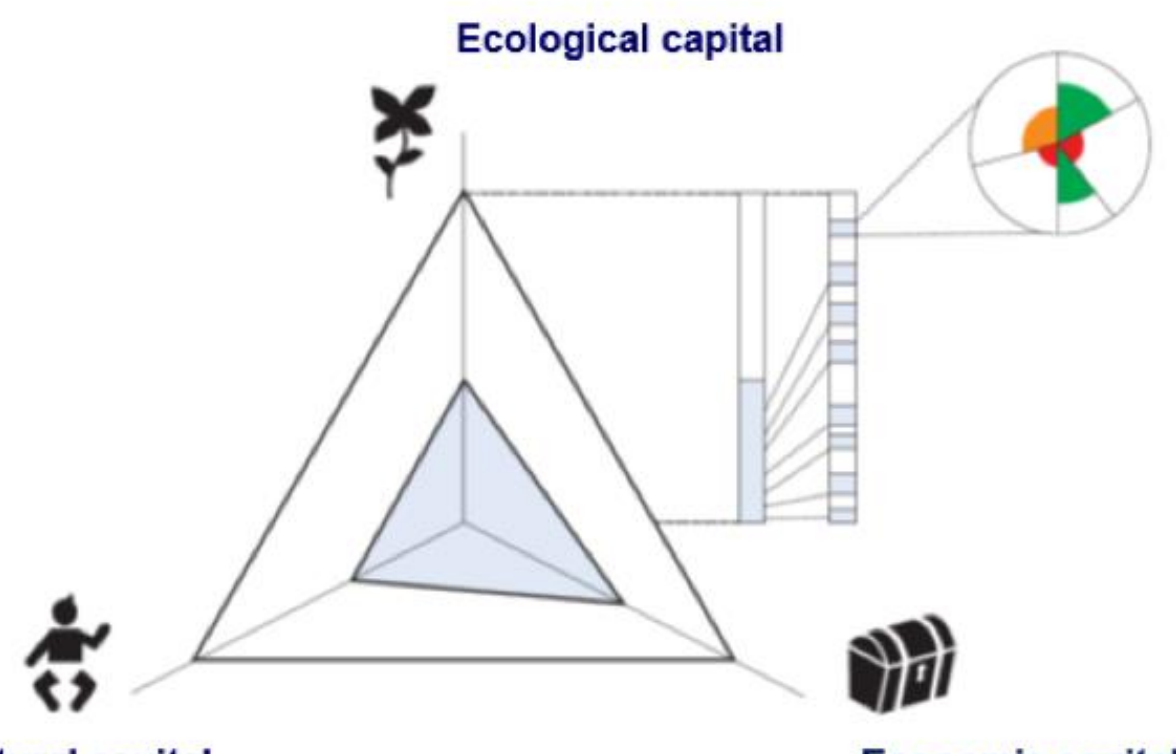

Socio-cultural capital

\section{Economic capital}

Figure 3. Community capital model informing the study. (Image provided by the Telos Brabant Centre for Sustainable Development, Tilburg Netherlands).

Between these stocks and the indicators used to measure them, local sustainability goals must reflect the priorities that are most important in the community or regional context; this process can occur through participatory (and lengthy) multi-stakeholder visioning and planning, or using a 
pre-determined set of goals and indicators [42]. Finally, the indicators are evaluated against benchmarks based on normative assessments of the state of each indicator (represented by the radial diagram in Figure 3). Figure 4 shows this process step by step.

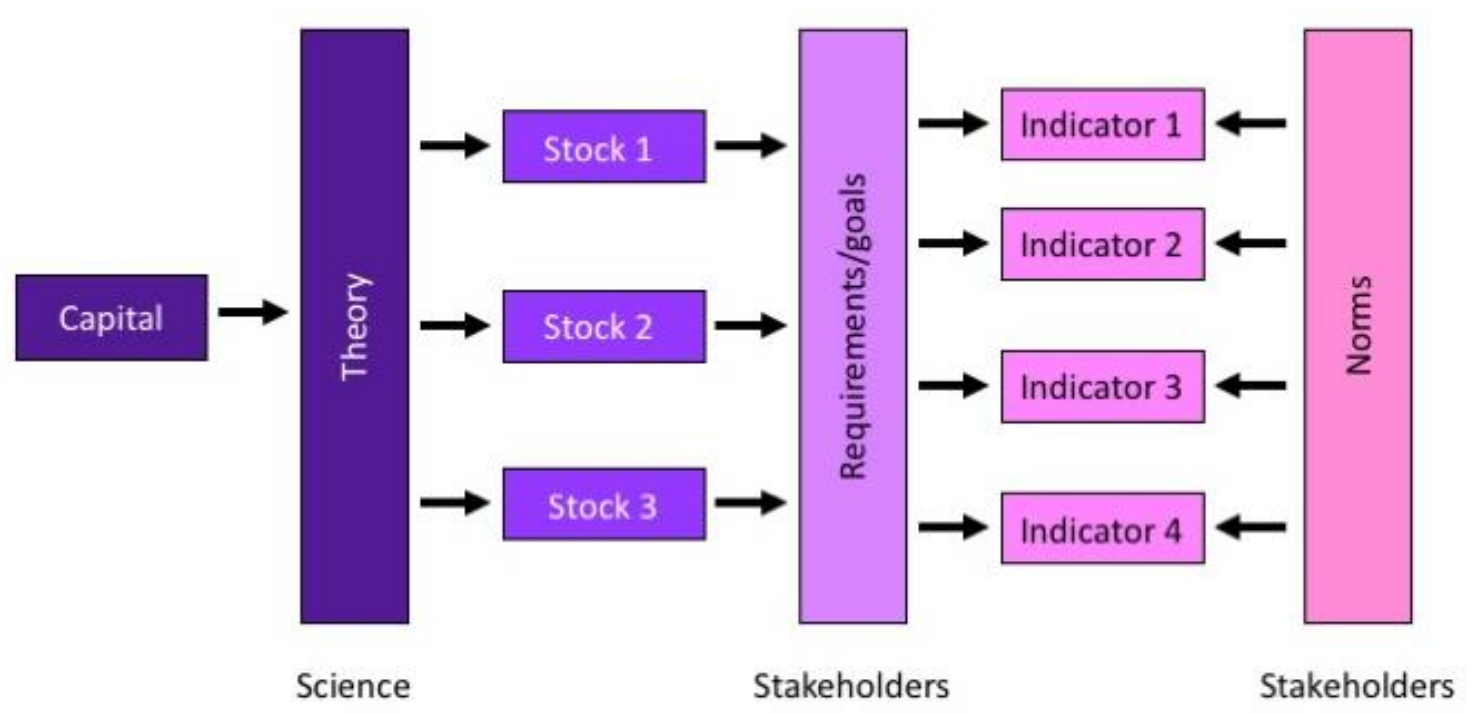

Figure 4. Identification of capital stocks and indicators through the Sustainability Balance approach. (Image adapted from Zoeteman et al.).

This analysis was organized according to the above approach, which guided our identification of key stocks based on the indicators used across the 39 SI initiatives, rather than evaluating the state of local indicators based on benchmarks. To determine key stocks among the SI initiatives, we used a blend of inductive and deductive content analysis [118], aggregating each initiative's goals and indicators and comparing them to these stocks. We initially identified a large number of inductive priorities, then refined them in comparison with the CCF stocks. Through this iterative process, we combined indicators that were duplicative (e.g., number of seniors vs. percent senior population), as well as similar stocks. We analyzed the frequency with which they appeared across initiatives, comparing stock-and indicator-level emphasis between initiatives, revealing what kinds of indicators were used to define SD in context and whether certain kinds of initiatives prioritized different stocks and indicators over others.

\subsection{Governance Analysis}

Finally, we examined case documents to determine the role of the initiatives in local governance. This assessment was informed by theories of shared decision-making, public participation, and collaborative and multi-level governance [19-21,51,54], insights on regional collaboration in rural Canada [23,24], and SI literature [11,16,18]. Using QSR Nvivo ${ }^{\mathrm{TM}}$ software, we assessed case documents based on the following criteria:

- Range of governance actors involved at different scales

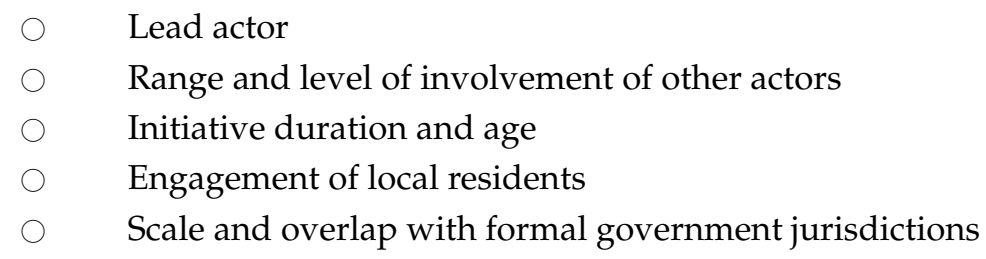

- Level of embeddedness in local SD priorities and related governance processes

$\bigcirc \quad$ Linkages with municipal or regional SD strategies 
Linkages with national/international frameworks

Incorporation of local priorities and perspectives

- Intended role in shared decision-making

Intended (or actual if applicable, depending on the initiative stage) uses of SI tool among different audiences

Depth of collaboration (in practice and/or envisioned) among actors

\section{Results}

\subsection{Community and Initiative Characteristics}

The SI initiatives identified in the inventory varied considerably in their community and regional contexts. Across all cases, the average population was 48,017 residents, ranging from a community of 601 residents to a region of 167,425 (see Supplementary Materials for a full list of case locations and related contextual factors); 19 initiatives (48.7\%) were in Census RST areas ( $<10,000$ residents). Of areas including a CA as their largest community, 25.6\% had a town between 10,000-39,999 inhabitants, $15.4 \%$ had a CA of 40,000-69,999 people, 5.1\% encompassed a small city between 70,000-99,999, and 5.1\% were on the fringes of a CMA. Figure 5 shows the distribution of initiatives across these census classifications and the average population of each grouping.

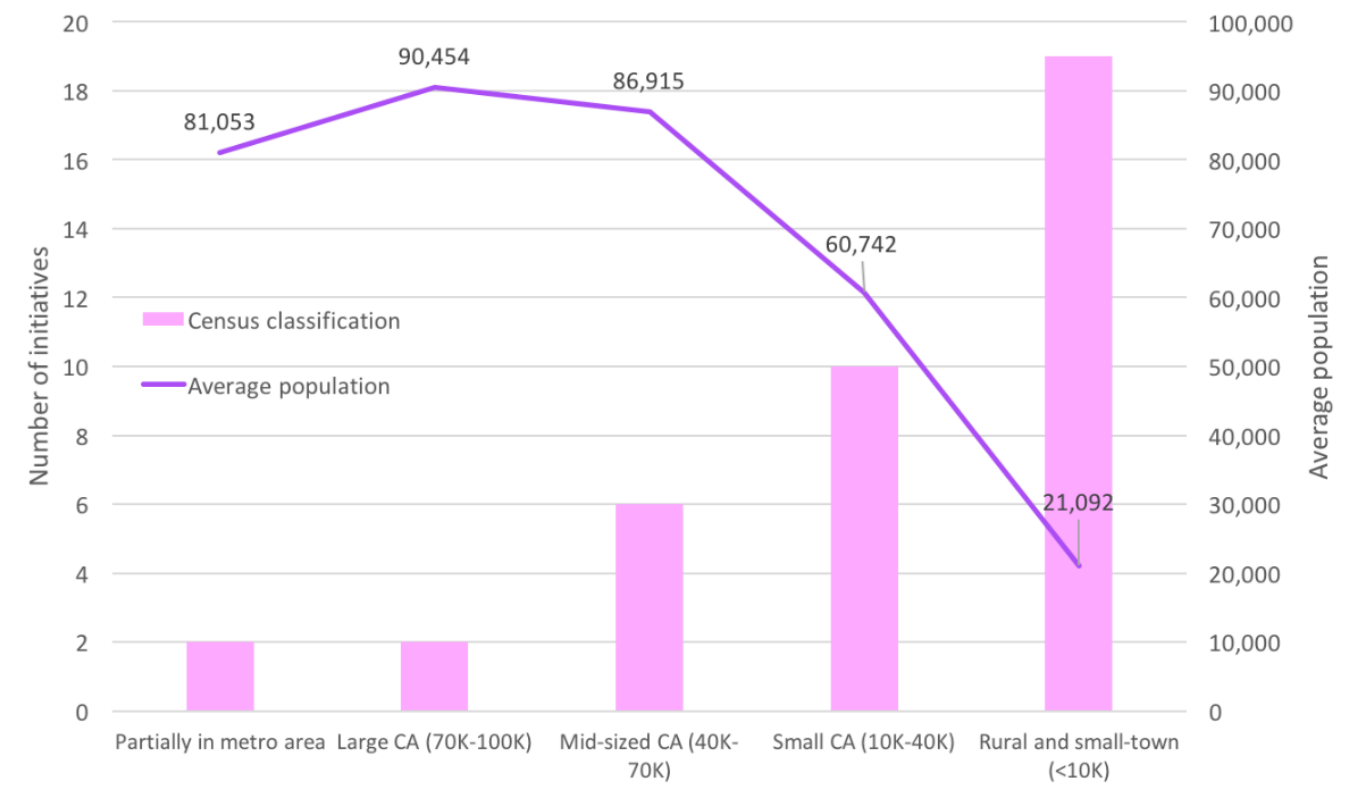

Figure 5. Distribution of SI initiatives across census classifications with average population. (Average population refers to the total population of the community or region considered in each initiative, not of the largest community (e.g., CA) included in that area).

The sample varied in demographic change between 2011-2016, ranging from $-4.6 \%$ (Temiskaming, $\mathrm{ON}$ ) to $+20.7 \%$ (Whistler, BC). However, the majority of communities and regions $(71.8 \%)$ were growing, with an average 5 -year growth rate of $+3.5 \%$ across all cases. The prevalence of natural resource occupations ranged from $1.3 \%$ (Whistler) to $20.9 \%$ (Robson Valley, BC), with an average of $7.4 \%$ of the local workforce based in these sectors. The average distance to a CMA was $183 \mathrm{~km}$, with 21 initiatives $(53.8 \%)$ less than $150 \mathrm{~km}$ from an urban center, 30.8\% in non-urban-adjacent areas (>150 km from a CMA), and 7.6\% each in small cities and remote Northern areas. Many communities with low resource dependence were heavily tourism-dependent (e.g., Whistler) or urban-adjacent (e.g., Headwaters, ON). 
In contrast, the most resource-dependent areas tended to be non-urban-adjacent, with communities that had over $10 \%$ natural resource dependence located an average of $291 \mathrm{~km}$ from the nearest CMA.

Considering these factors, the initiatives were clustered within a particular range. Most communities were relatively urban-adjacent, had a low level of dependence on resource sectors, and stable or growing populations, as shown in Figure 6.

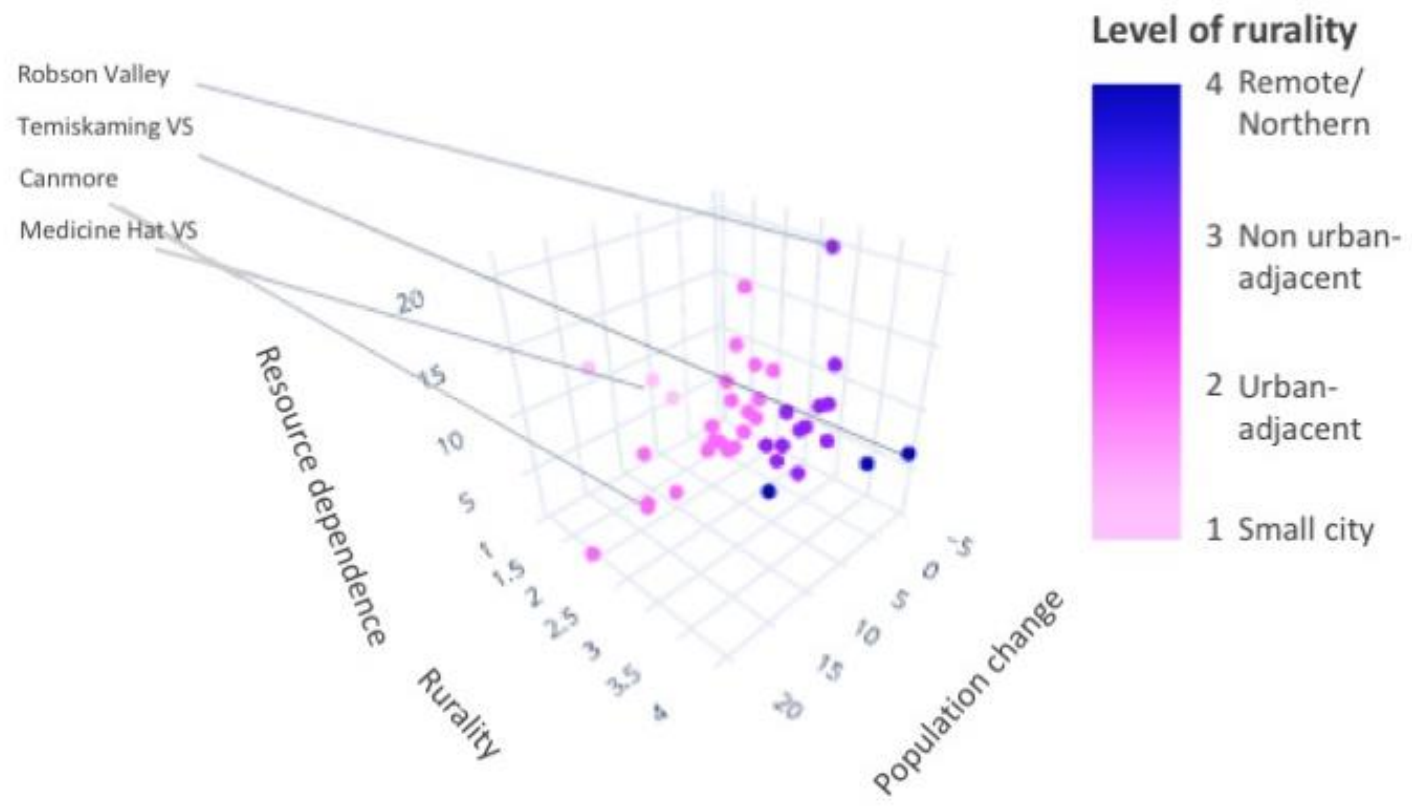

Figure 6. Distribution of initiatives across geographic and socio-economic factors.

There were several outliers, like the Robson Valley, a relatively remote region in BC's interior that is heavily forest-dependent and declining demographically, and Canmore, $\mathrm{AB}$, a tourism-dependent community near Calgary facing rapid growth. Two of the three remote/Northern initiatives were conducted by Indigenous Peoples in very remote areas (discussed below), with the remaining initiative a Vital Signs (VS) initiative from Northern Ontario. These stood in contrast to small cities (VS projects in Medicine Hat, AB, Prince George, BC, and Brandon, MB), all of which depended historically on natural resources or continue to do so.

\subsection{Rural SD Priorities and Indicators}

We identified 1073 indicators across all initiatives, beginning with 20 basic stocks (see Figure 1) but adapting them substantially to reflect 28 overarching priority areas in which these indicators were organized across project documents. The initiatives placed the greatest emphasis on socio-cultural capital, using 681 indicators $(63.5 \%)$; prevalent socio-cultural stocks included physical health (109 indicators total), education (82), and housing (66). The second-most emphasized capital was economic (222 indicators, or 20.7\% of total), prioritizing economic structure (72 indicators), labor (63), and transportation (50). Ecological capital was measured by 170 indicators ( $15.8 \%$ of total), emphasizing ecosystems (56 indicators), waste reduction (22), and climate change and energy (22).

Figure 7 reveals the most prioritized areas of rural SD and those that were under-emphasized. Of the latter, ecological stocks like air quality and natural resources were relatively under-prioritized, as well as financial resources in economic capital and gender equity in socio-cultural capital. Comparing stock-level emphasis by level of rurality, Figure 8 shows how factors like urban adjacency or remoteness affected the SD priorities considered. Since two of these categories (small city and remote/Northern) had only three cases, we applied a uniform weighting (calculating the proportion of indicators per stock across geographic types) to compare their prioritization of stocks. 


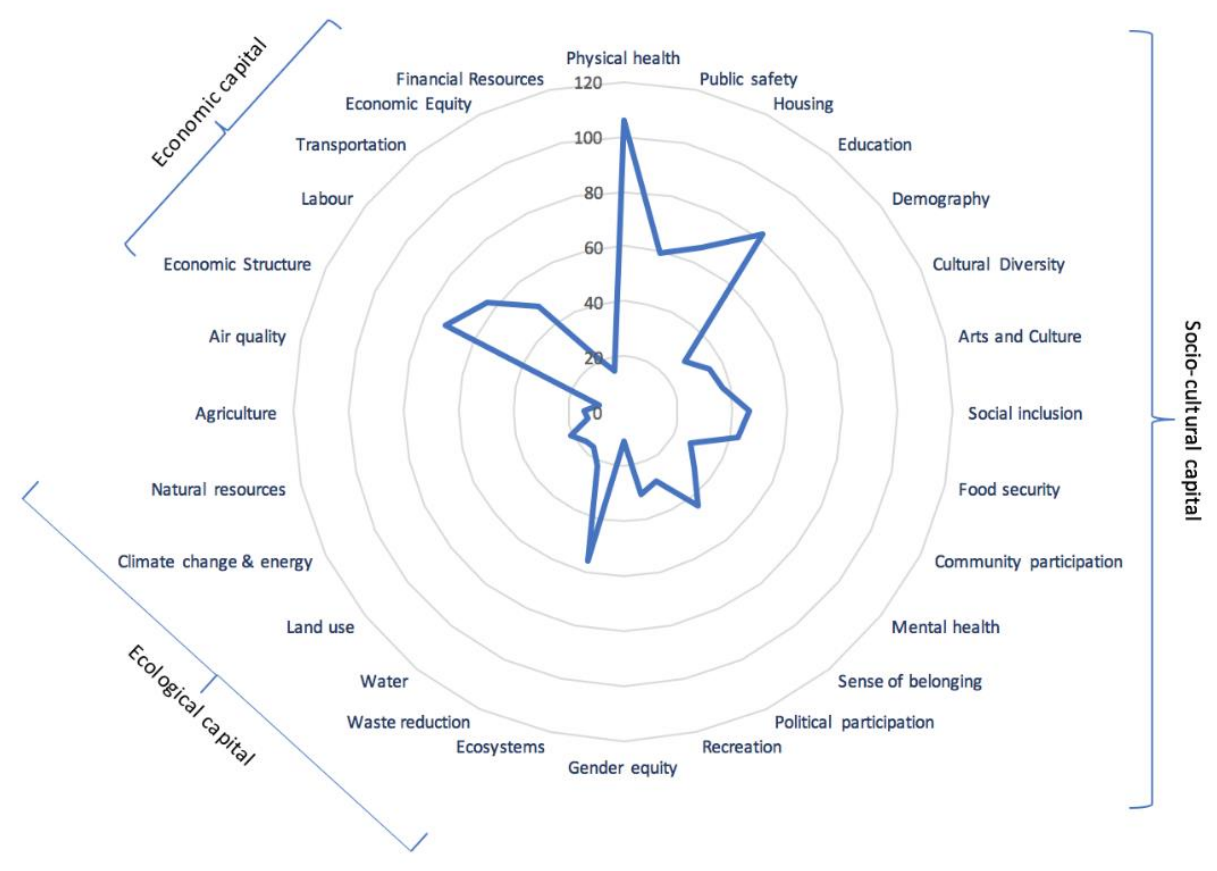

Figure 7. Stock-level emphasis on community capital (number of indicators per stock).

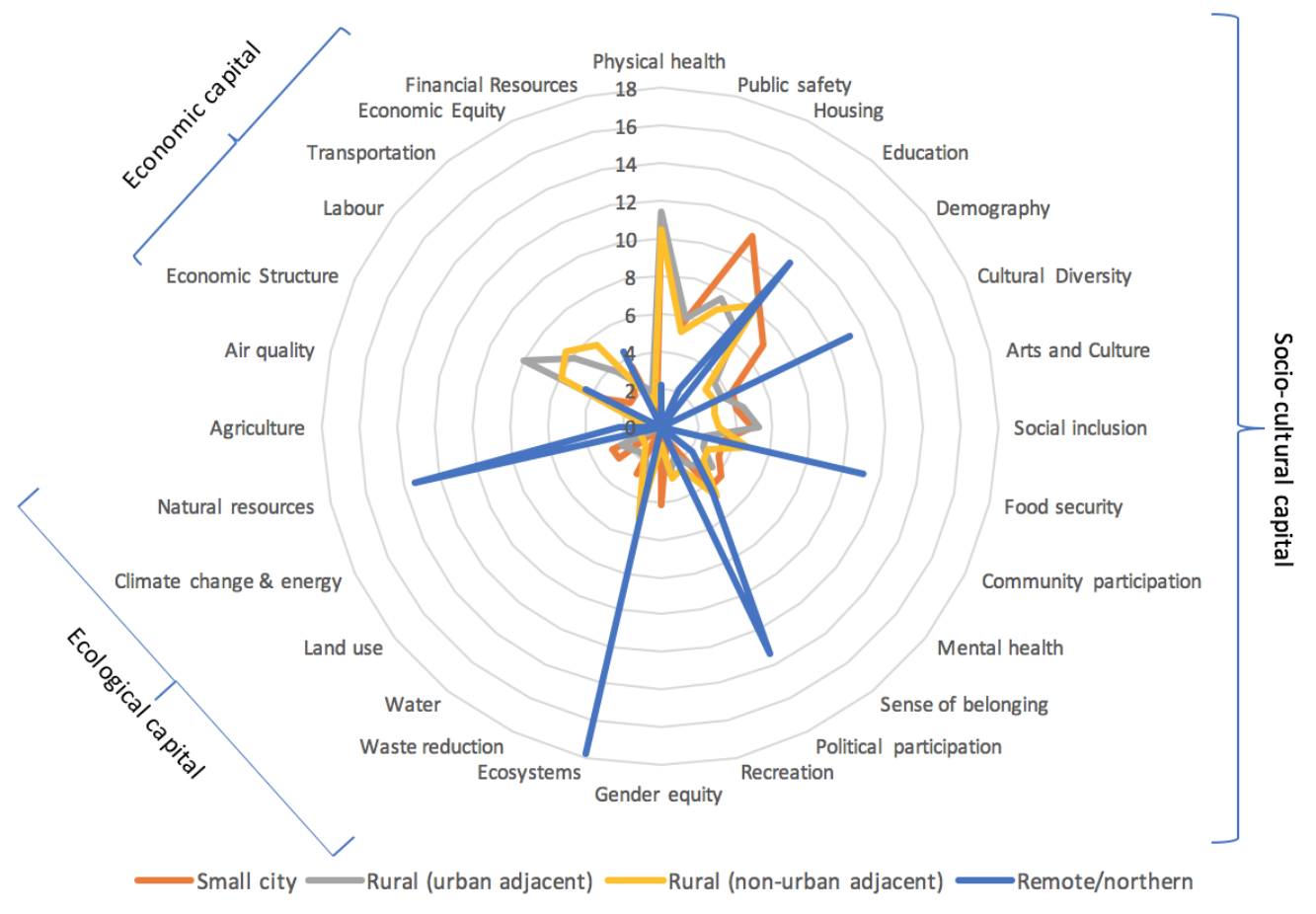

Figure 8. Stock-level emphasis by level of rurality (weighted to 100).

As shown above, remote/Northern areas were the only geographic category that departed considerably in their stock-level emphasis. Two of these initiatives were led by First Nations, whose indicators were informed by Indigenous cultures and worldviews. For example, the Little Red River Cree Nation (LRRCN) articulated indicators like "community elders receive the meat harvested from trophy hunts" [114], which simultaneously related to natural resources, ecosystems, food security, and cultural diversity (see Section 4). 
These initiatives used several kinds of indicators. Official indicators (typically collected by government agencies like Statistics Canada) provide standardized statistical values to represent the current state of a given issue, contrasted to indicators measuring inputs of administrative or financial resources or survey responses gauging resident attitudes. For example, vehicular accidents may be low according to Census data or local police records, but residents (or a subset of the population like seniors) may still perceive that local driving conditions are unsafe, while policy inputs like municipal budgets for traffic calming measures may be increasing. These indicator types often overlap, (e.g., the inclusion of many perceptual indicators in official data collected by Statistics Canada). We coded all indicators using these categories and compared their frequency across stocks (Figure 9), also identifying aspirational indicators which were framed as sustainability goals describing the direction in which indicators were intended to move. For example, an aspirational indicator like "assist with the retention and expansion of local businesses" was only used in one initiative (Huron County, ON), contrasted with official indicators like the number of new businesses licenses per year (used by seven initiatives). Living wage was the most popular aspirational indicator (used by 10 initiatives), aiming to bring average wages to a livable level, often based on local living wage studies.

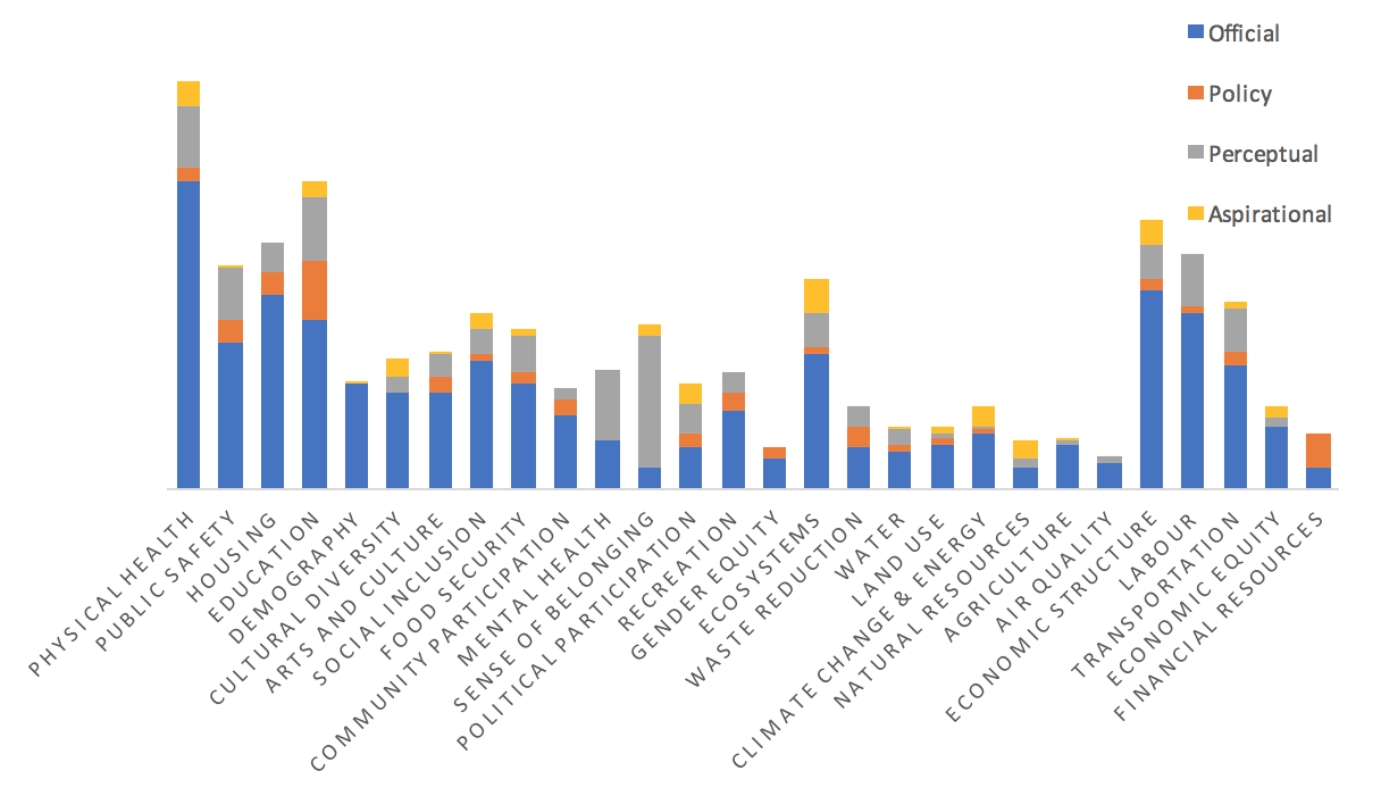

Figure 9. Indicator types across initiatives (percentage of total indicators per stock).

The most common indicator type was official data (65.6\% across all initiatives), followed by perceptual (19.9\%), policy (8.2\%), and aspirational (6.3\%). Policy indicators were common among education (e.g., public spending per student), housing (e.g., number of affordable housing units built by local authorities), and financial resources (e.g., property tax rates). Unsurprisingly, many policy indicators fall within the jurisdiction of local authorities. Conversely, some stocks (e.g., mental health, sense of belonging) relied heavily on perceptual indicators, reflecting the nature of these issues. Perceptual and official indicators were often paired, especially those collected by Statistics Canada (e.g., measuring self-perceived sense of belonging to community alongside community members' average length of residency). A small number of initiatives blended these four indicator types, but the majority predominantly relied on official and perceptual indicators.

A major reason for the predominance of official indicators was their common use in VS projects, which were often organized in a uniform list of priority areas like Health, Learning, Economy and Work, and Environment (adapted from CFC, 2018, 20:16; see Supplementary Material for a list of these priority areas and standard indicators). This framework directly influenced the indicators used in local VS reports. For example, of the 15 most common indicators across VS reports, many are sourced from 
this standard indicator set. Most of the common indicators used by both VS and non-VS initiatives (including grassroots projects (10) and CIW (2)) correspond to socio-cultural capital. Although many of these indicators were used by both groups (e.g., unemployment rate, perceived sense of community belonging), non-VS projects prioritized some indicators not often used by VS. For example, waste diversion rate was used by $41.6 \%$ of non-VS initiatives (5/12), the only ecological indicator to appear in their top 15 list, whereas only $22.2 \%$ (6/27) of VS reports included this indicator. Similarly, the number of business licenses issued annually was used in $33.3 \%$ of non-VS projects (4/12), but only $11 \%$ of VS reports (3/27). See Supplementary Material for the 15 most commonly used indicators in VS and non-VS initiatives.

The large number of VS initiatives influenced the stocks prioritized across the sample (e.g., physical health, education, housing). In contrast, non-VS initiatives placed greater emphasis on ecosystems and economic structure, while converging on labor, housing, and of sense of belonging, and slightly weighting social inclusion and political participation higher than VS initiatives. Figure 10 compares the holism of these initiative types, accounting for the over-representation of VS initiatives by applying a uniform weighting so that each stock's weight is converted to a proportion of the total number of indicators across initiative type.

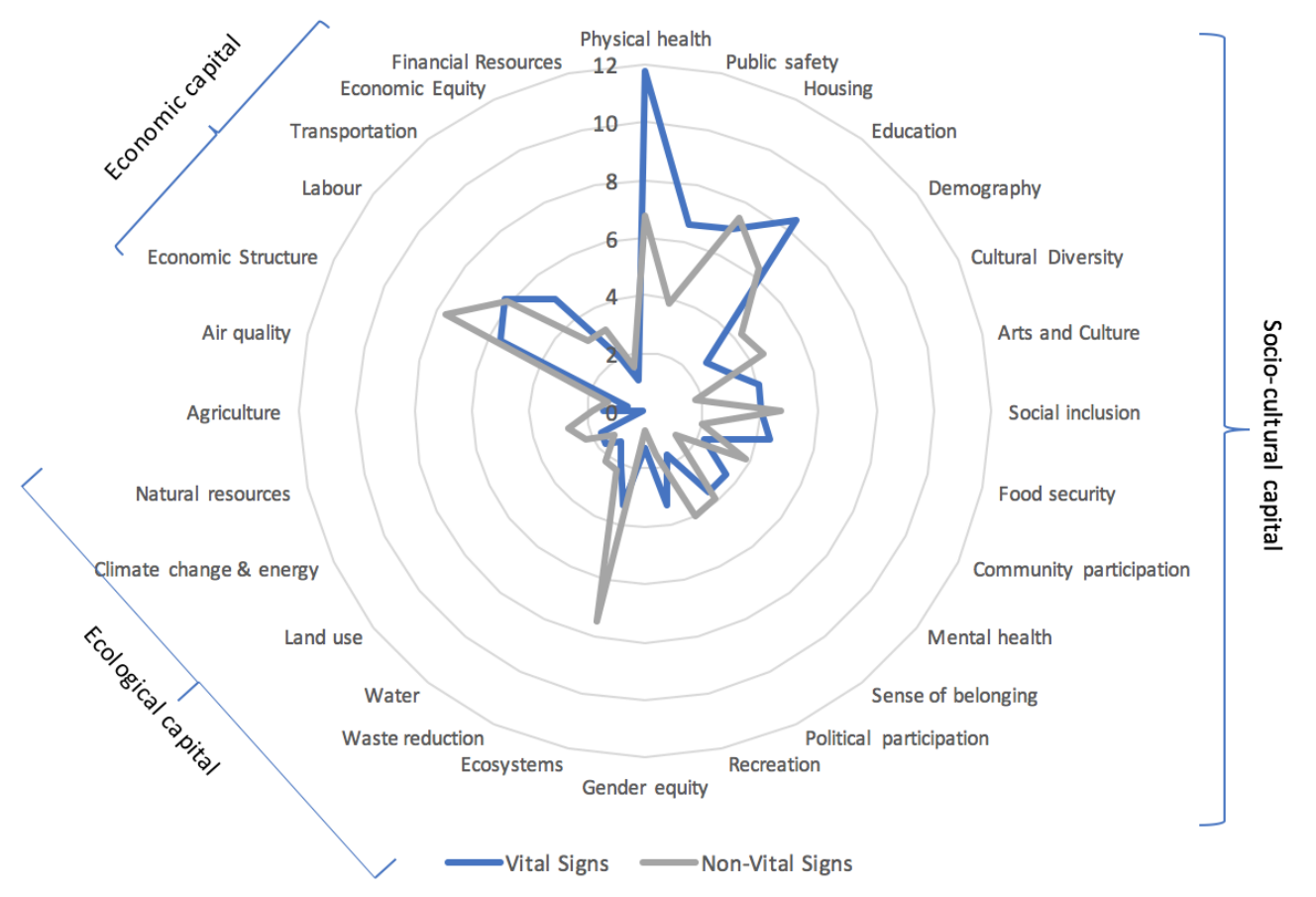

Figure 10. Stock-level emphasis by initiative type (weighted to 100).

Among non-VS initiatives, grassroots projects also differed considerably from CIW initiatives. Only two CIW projects were included in the inventory (Oxford County and My Perth-Huron), which prevented a meaningful analysis of differences across stocks and indicators due to the low sample. However, at the capital level, these initiatives had very little variation from VS projects, while grassroots initiatives had a stronger emphasis on ecological and economic capitals. Figure 11 shows the relative emphasis on forms of community capital, applying a uniform weighting by converting the number of capital-based indicators into a proportion of the total indicators per initiative type. 


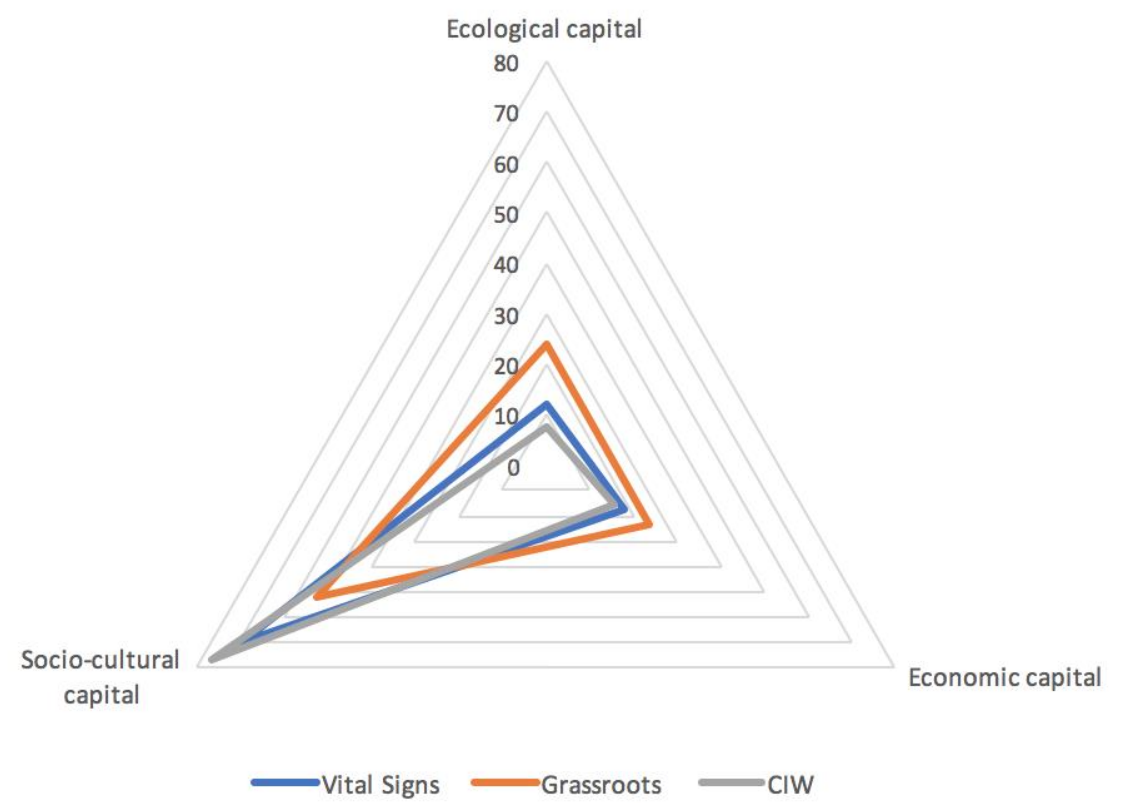

Figure 11. Capital-level emphasis of initiative types (weighted to 100).

As shown above, socio-cultural capital takes precedence across all initiative types, although grassroots initiatives were somewhat more balanced than VS and CIW (which were almost identical in capital-level emphasis) due to more frequent use of ecological and economic indicators. Returning to the stock level, some stocks (e.g., gender equity, air quality, and financial resources) were under-emphasized across all initiative types, potentially revealing gaps in a rural SD agenda.

\subsection{Governance Assessment}

\subsubsection{Leading Actors}

The approach that each initiative used to measure local SD was strongly influenced by its lead organization. The VS project, to which $69 \%$ of the sample belongs, is a national project coordinated by Community Foundations of Canada (CFC), which supports community foundations [25], a specific type of charitable organization that accepts donations and distributes grants to other charities within a defined geographic area [119]. Thus, the lead actor for most initiatives was a non-profit organization (29 initiatives, or 74.3\%), including two initiatives not affiliated with VS Other lead actors (representing $25.7 \%$ of the sample) included municipalities, regional governments (e.g., county, regional district), Indigenous nations, or academic researchers. Among non-VS projects, lead actors were spread relatively evenly across initiatives. The lead actors across initiatives are shown in Table 1, along with their scale (discussed below).

Table 1. Distribution of SI initiatives by lead actor and scale.

\begin{tabular}{cccccc}
\hline Lcale Actor & Non-Profit & Municipality & $\begin{array}{c}\text { Regional } \\
\text { Governing Body }\end{array}$ & $\begin{array}{c}\text { Indigenous } \\
\text { Nation }\end{array}$ & Academic \\
\hline Municipal & 5 & 2 & 0 & 0 & 0 \\
\hline Metropolitan Area & 2 & 0 & 0 & 0 & 0 \\
\hline Administrative Region & 10 & 0 & 2 & 0 & 1 \\
\hline Multi-county & 3 & 0 & 0 & 0 & 0 \\
\hline Non Administrative Region & 9 & 0 & 1 & 0 & 2 \\
\hline Indigenous Territory & 0 & 0 & 0 & 2 & 0 \\
\hline Total & 29 & 2 & 3 & 2 & 3 \\
\hline
\end{tabular}




\subsubsection{Scale and Jurisdictional Overlap}

These driving actors were directly related to the scale at which initiatives were carried out. The most common scale was a designated administrative region (e.g., county, regional district), representing $33.3 \%$ of initiatives. In contrast, the second most common scale (30.8\%) was a region based not on administrative or metropolitan boundaries, but some other regional scope. Often, these areas were based on eco-regions (e.g., Columbia Basin-Boundary region of BC, Lacloche Foothills in ON). Less frequent scales included municipal boundaries (seven initiatives, or 17.9\%), multi-county regions $(7.6 \%)$, metropolitan areas of a small resource-based city, and Indigenous territories $(5.1 \%$ each). Incidentally, these designations also represent aggregation levels for which Statistics Canada data are readily available (except for non-administrative region and Indigenous territory), implying that the availability of data at the appropriate geographic scope is also closely related to the chosen scale. Table 1 reveals two main clusters at the regional level, but in both administrative and non-administrative regions these initiatives were driven primarily by non-profit organizations (community foundations in all but one of 19 cases). A similar pattern is seen at the municipal scale, which instead of being driven by the municipality were led by community foundations in $5 / 7$ cases.

\subsubsection{Initiative Duration and Age}

To assess each initiative's duration, we examined how many iterations of the indicator tool had occurred, the overall length of time that the project has existed, and the frequency with which it has been updated (e.g., new report). Since in many cases it was unclear based on publicly available documents whether an initiative was still active (especially older initiatives), we calculated each initiative's duration based on the length of time between the first iteration (e.g., inaugural indicator report) and the most recent available. For example, if a VS released its first report in 2011, and its most recent in 2018, we noted a duration of seven years (as opposed to nine, which could incorrectly assume that the initiative was still active when it may have gone inactive since 2018). We considered documents going back to 1999 and as recent as 2019.

The average initiative duration was 4.5 years, with the two longest-running initiatives also the only municipal-led projects (Canmore, AB at 19 years and Whistler, BC at 13). Conversely, 11 initiatives appeared to have only had one iteration, including relatively new initiatives (e.g., Selkirk VS, launched in 2018), and projects that occurred over 10 years ago (e.g., Robson Valley). This project, along with another academic-led initiative (Oxford County, ON), appeared to have no follow-up (contrasted to an academic-led project in the Kootenays region of BC that had regular updates over a five-year period). Overall, 20.5\% of initiatives started between 1999-2009, 43.6\% between 2010-2014, and 35.9\% between 2015-2019. The average frequency of updates was 3.1 years. Figure 12 compares average initiative duration across lead actor types, highlighting the marked longevity of municipal-run projects among other initiative types.

\subsubsection{Stakeholder Engagement}

All initiatives discussed engaging the general public, such as community foundations communicating to potential donors or local governments aiming to involve citizens in decision-making. $66 \%$ of initiatives intended to engage local governments, both by informing municipal or regional decision-making and working with governments as partners. $30.8 \%$ of initiatives aimed to engage the private sector (e.g., informing tourism investment or resource development projects), while many more mentioned local businesses as sponsors or engaged consultants and think tanks to conduct the project. Only $15.4 \%$ of initiatives discussed engaging provincial or federal government agencies, often as a funding agency or a source of policy decisions that affect local conditions. We discuss the nature in which these stakeholders were involved more in-depth below. 


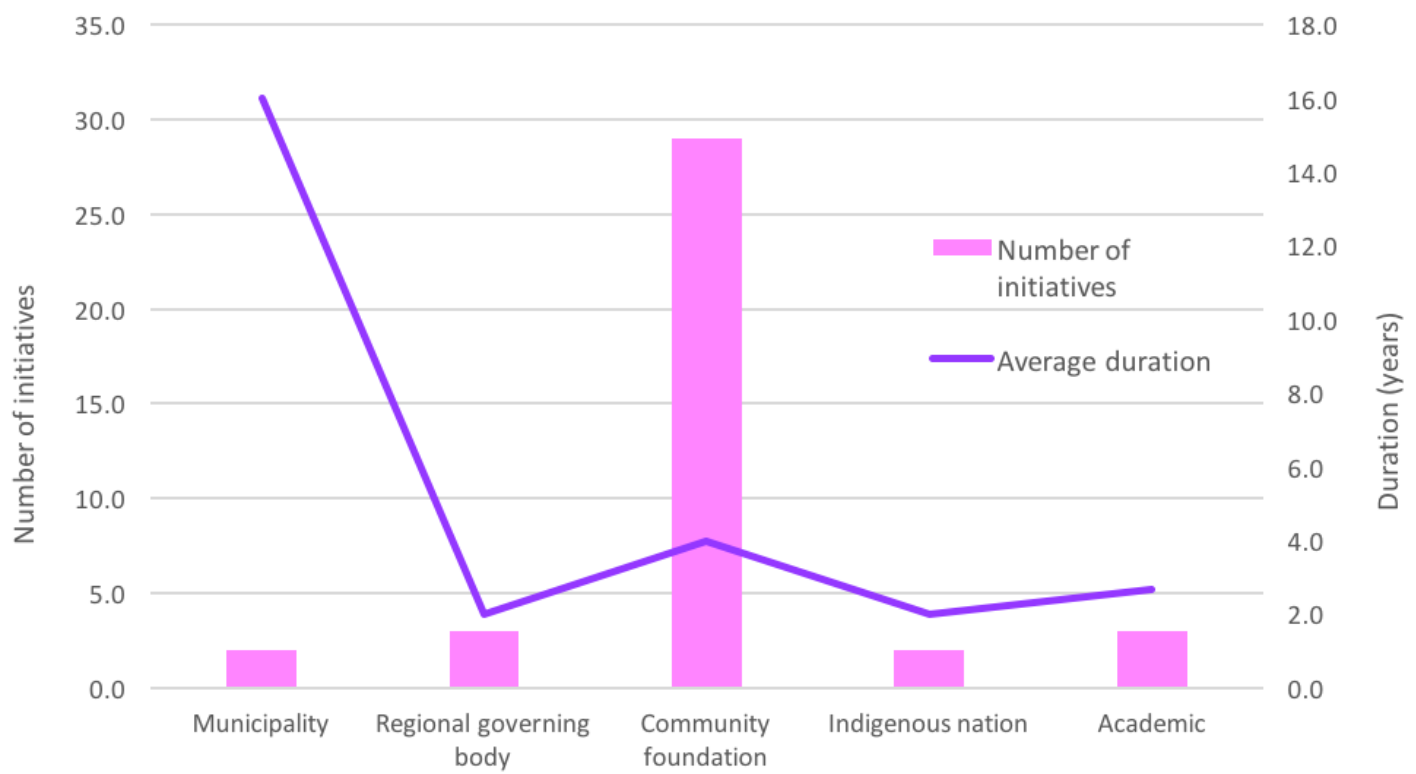

Figure 12. Average initiative duration by lead actor.

The initiatives varied widely in efforts taken to involve local residents. Overall, $56 \%$ of initiatives surveyed local residents, which is a common practice in VS projects and is sometimes paired with other engagement methods like meetings with subject matter experts or group consultations. Of the initiatives, $25.6 \%$ combined surveys with consultation sessions, and only $12.8 \%$ used workshops without a survey. Some surveys provided rich perceptual data to complement (or contrast) official data, like the Columbia Valley VS which gauged resident perceptions about regional amenities ranging from natural beauty to employment opportunities. In a few cases, these in-depth consultation methods were part of community-based research projects in which extensive data collection enriched the depth of engagement (e.g., LRRCN, Naskapi Nation, Clarenville-Bonavista).

\subsubsection{Embeddedness in Local Priorities and Perspectives}

To gauge how embedded the initiatives were in local SD priorities, we considered both whether grassroots initiatives were informed by high-level priorities and if national-level frameworks referenced local policy and planning priorities. Using qualitative rankings (high, medium, low), we assessed to what extent each initiative discussed local (municipal or regional) policies and plans, national frameworks or policies (e.g., VS, CIW), and international agendas (e.g., SDGs).

The initiatives occurred along a spectrum of balancing top-down and bottom-up approaches. Seven initiatives $(17.9 \%)$ were heavily embedded in local policies and plans, including both municipal-led initiatives (which were part of the municipalities' sustainability planning processes), both Indigenous-led initiatives, two led by regional governing bodies (Clarenville-Bonavista and Huron County), and one academic-led project (State of the Basin). Several of these initiatives also used aspirational indicators, like Huron County, which phrased all of its indicators as policy goals. Twenty-six initiatives $(66.6 \%)$, in contrast, minimally engaged local policy priorities (including 24 VS and two academic-led initiatives). Six initiatives (15.3\%) took an intermediate approach, engaging local perspectives while remaining aligned to higher-level priorities and frameworks, including three VS projects, one led by a regional governing body, and two by other non-profits. For example, Lennox and Addington County reorganized the VS framework around the SDGs while using local resident consultations to identify which of the global goals were most salient for the region.

This assessment revealed a data-driven approach to measuring local sustainability priorities. As discussed in Section 3.2, many VS initiatives relied on a standard set of categories and indicators derived from the national framework (see Supplementary Materials). Since initiative scale so often overlapped with administrative boundaries (and thus data aggregated at the appropriate geographic 
level), the standard VS framework also seemed to be connected to data availability. As will be discussed in Section 4, local VS projects also rely on the national organization (Community Foundations of Canada, or $\mathrm{CFC}$ ) for access to these data, which are presented in the standard framework. For example, the North Okanagan VS report describes that "[m]uch of the data within this report was collected by the CFC's data partner, the International Institute for Sustainable Development" [120]. In total, $55.6 \%$ of VS initiatives followed this data-driven approach, applying a standard framework and indicators with minimal incorporation of local perspectives. In these data-driven VS projects, there appeared to be little effort to contextualize this standard framework and dataset within local priorities and perspectives.

Nonetheless, other VS initiatives took a more contextualized approach. Clayoquot Sound, BC included extensive conservation indicators from recent ecological studies and transportation indicators relevant to the region's island geography, as well as traditional knowledge from First Nations living in the region and local resident surveys. In an intermediate range, a handful of initiatives balanced official data with local resident perspectives, often derived from consultation sessions or surveys. These intermediate initiatives often incorporated stories to enrich the information portrayed by the indicators, like local residents' anecdotes and examples of community initiatives aimed at addressing identified needs. The Medicine Hat, AB project described the narrative style of its 2017 report:
"This year, you will discover that our publication looks a bit different from years prior. Our new layout is still informative, inspiring, and tells people the story of Medicine Hat and Southeastern Alberta. We've highlighted some powerful stories this year, focused on our theme of 'Belonging: Connection to Community' and are intrigued to hear what you think that means" [121].

\subsubsection{Governance Uses of Indicators}

We identified five overarching forms of intended SI use across the initiatives: informing the public, influencing governmental decision-making, informing economic development, encouraging multi-stakeholder dialogue, and demonstrating the need for (or impact of) granting activity. All initiatives expressed some desire to inform or engage the public, although the nature of this engagement (as discussed below) was envisioned very differently across initiatives. Due to the large number of VS initiatives, the majority $(71.8 \%)$ described the instrumental use of supporting the granting activities of the community foundation, both by highlighting needs among the population and demonstrating the impact of previous grants. Eleven initiatives (28.2\%) expressed a desire to influence economic development, intending to inform decisions about economic opportunities and threats related to key sectors like natural resource industries and tourism. For example, the two Indigenous initiatives were concerned about resource extraction activities (i.e., forestry and mining), aiming to use the indicators to influence management decisions, while highly tourism-dependent municipalities like Whistler, BC sought to guide future tourism investment and economic development planning. Only two VS initiatives had a clear economic development focus (Clayoquot Sound and Columbia Valley), both of which expressed concern over managing growth in a sustainable manner in light of tourism activity and in-migration. An inter-related use was informing government decision-making, which was discussed by $58.9 \%$ of initiatives. $58.9 \%$ of initiatives also expressed an interest in facilitating discussion among multiple stakeholders in the community or region. Figure 13 shows these intended uses, represented as the percentage of initiatives (weighted to 100) by stakeholder type that described each form of use.

These intended uses varied considerably between non-profits (dominated by community foundations) and other stakeholder types. The former were often interested in using the SIs to justify their granting activity and inform residents of these efforts. In some cases, this was expressed in strategic terms, like the Brandon, MB report which stated that "[preparing] a Vital Signs report is an excellent way to begin to build our profile and role in our community" [122]. In contrast, initiatives led by municipalities and regional governing bodies (e.g., counties, Indigenous nations) were interested in using the indicators to inform their own decision-making and increase public participation. For example, the Canmore Community Monitoring Report aimed to “ . . increase citizen participation 
in local government, create opportunities for economic development, and inform decision making in both the private and public sectors" [123]. Academic initiatives featured both a broad set of intended uses across stakeholder groups (i.e., State of the Basin) and projects that seemed not to consider how local actors would use the indicators after the project ended (i.e., Oxford County).

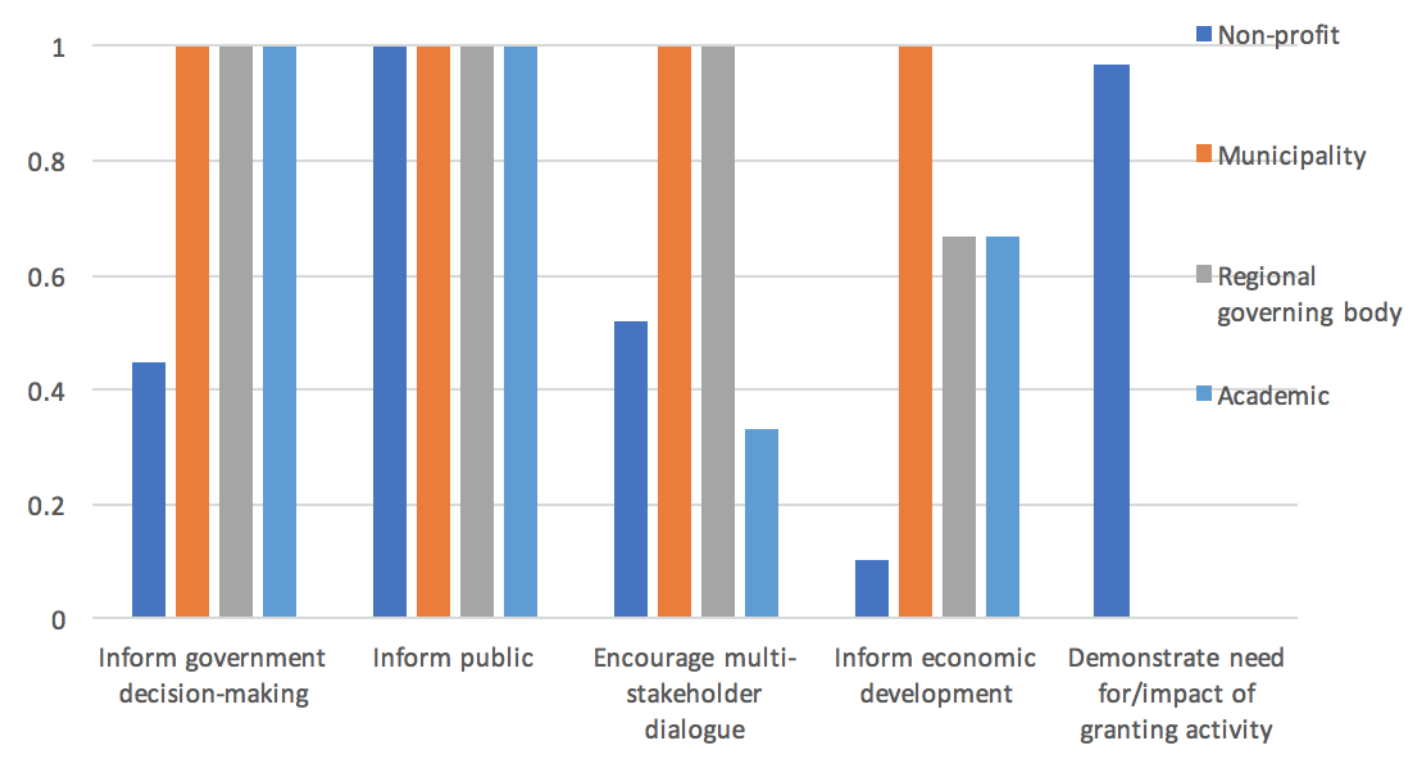

Figure 13. Intended uses of initiatives by lead actor (weighted to 100).

These priorities also relate to the use of aspirational indicators by the Indigenous initiatives and a handful of other actors, which were often linked to existing local policy and planning priorities. For example, LRRCN used exclusively aspirational indicators, designed both as a planning tool for the Band government and to represent the cultural importance of caribou and forests for its members in support of Indigenous self-determination.

Finally, there was a common interest among all initiative types to use the indicators to facilitate multi-stakeholder dialogue, although they placed differing emphasis on this goal and envisioned it in multiple ways. Many VS projects expressed the shallow aim of starting conversations among residents, often with an exclusively individual focus. For example, the Strait Region, NS project expressed that:

"We hope that this report serves as an 'At A Glance' information source to stimulate vital conversations among community members, support the important work that is being done, and reinforce efforts and investments needed" [124].

In contrast, more locally-driven VS projects called for different stakeholder groups to come together to discuss their goals for a sustainable community or region, articulating clear conceptual and instrumental uses. The Columbia Valley report articulated this goal in the following way:

"Vital Signs provides an opportunity to delve deeper into issues of concern by inspiring and informing community conversations and testing prototypes. Vital Signs is more than a one-off snapshot of our communities; it provides a benchmark against which to measure our progress and results in the future" [125].

Such initiatives described meaningful community engagement as a crucial element in using the indicators to bring together diverse stakeholder groups like forestry companies, property developers, seasonal residents, municipalities, and First Nations to discuss solutions to identified challenges. These more bottom-up initiatives also envisioned the indicators as a way to track the impact of collective efforts over time and influence new projects and policies. 


\subsubsection{Depth of Stakeholder Collaboration}

Similarly, initiatives occurred across a spectrum of collaborative practices. On one end, initiatives driven by strategic instrumental goals tended to engage with other stakeholders in a relatively shallow manner. Many VS reports claimed to embody collaborative principles but only discussed the involvement of other stakeholder groups in terms of resources they provided to the project (e.g., funding, data). VS reports often discussed local agencies that provided data, like school districts, police, libraries, and homelessness support groups, but rarely described whether these groups informed the design of the project beyond data provision. Furthermore, some initiatives seemed not to consider these groups in the ongoing role of the tool itself, reflected in this quotation from Lunenburg County VS:

"Through this report, we are giving all community members the facts in a clear and unbiased fashion about how our community is faring. Let this report assist and inspire us to bring about changes that will improve the quality of our lives now and in the future" [126].

This excerpt is reflective of VS projects that primarily addressed individual residents, recommending actions at the household level but overlooking collective responses or the role of local agencies that provided data to the project. Twenty-three VS projects $(85.2 \%$ of VS and $58.9 \%$ of the overall sample) took this non-collaborative approach, as did the two CIW initiatives.

In contrast, 10 initiatives ( $26 \%$ ) enshrined multi-stakeholder dialogue and collective action. Led by a wider variety of lead actors (including one VS), these projects engaged a similarly broad range of stakeholders, including local residents, provincial and federal government, businesses and business support agencies, think tanks, consultants, and social services. Reports discussed the roles played by such stakeholders in project design (which were often significant and ongoing), and collective action to improve the indicators. Examples include participation in meetings, project management, data collection and analysis, and providing feedback on the indicators. One particularly collaborative initiative, Headwaters Communities in Action, discussed this process:

"HCIA, our grassroots citizen group, wanted to know what community well-being meant to you, so we asked and residents answered us. This report reflects upon what we heard and, we hope, will initiate conversations that move us to collective action for vibrant, just and sustainable community living" [127].

On an intermediate level, four VS initiatives embodied some of these collaborative principles, engaging a similarly wide group of stakeholders but often relegating these partners to more limited roles and conducting less in-depth community engagement methods.

Based on the governance features discussed above, we grouped all initiatives into a typology that differentiates their approaches to SI design and use. Informed by Arnstein's ladder of participation [55], Himmelmann's continuum of collaboration [56], and collaborative and multi-level governance theories [20,53], we delineate a range of collaborative practices, considering whether multi-stakeholder engagement efforts featured genuine collaboration versus more shallow interactions like networking or information-sharing, and the level of meaningful public participation. Finally, we articulate different forms of SI use, borrowing from Hezri and Dovers' typology [16] and subsequent discussions on instrumental and conceptual SI use [3,18], as shown in Figure 14. 


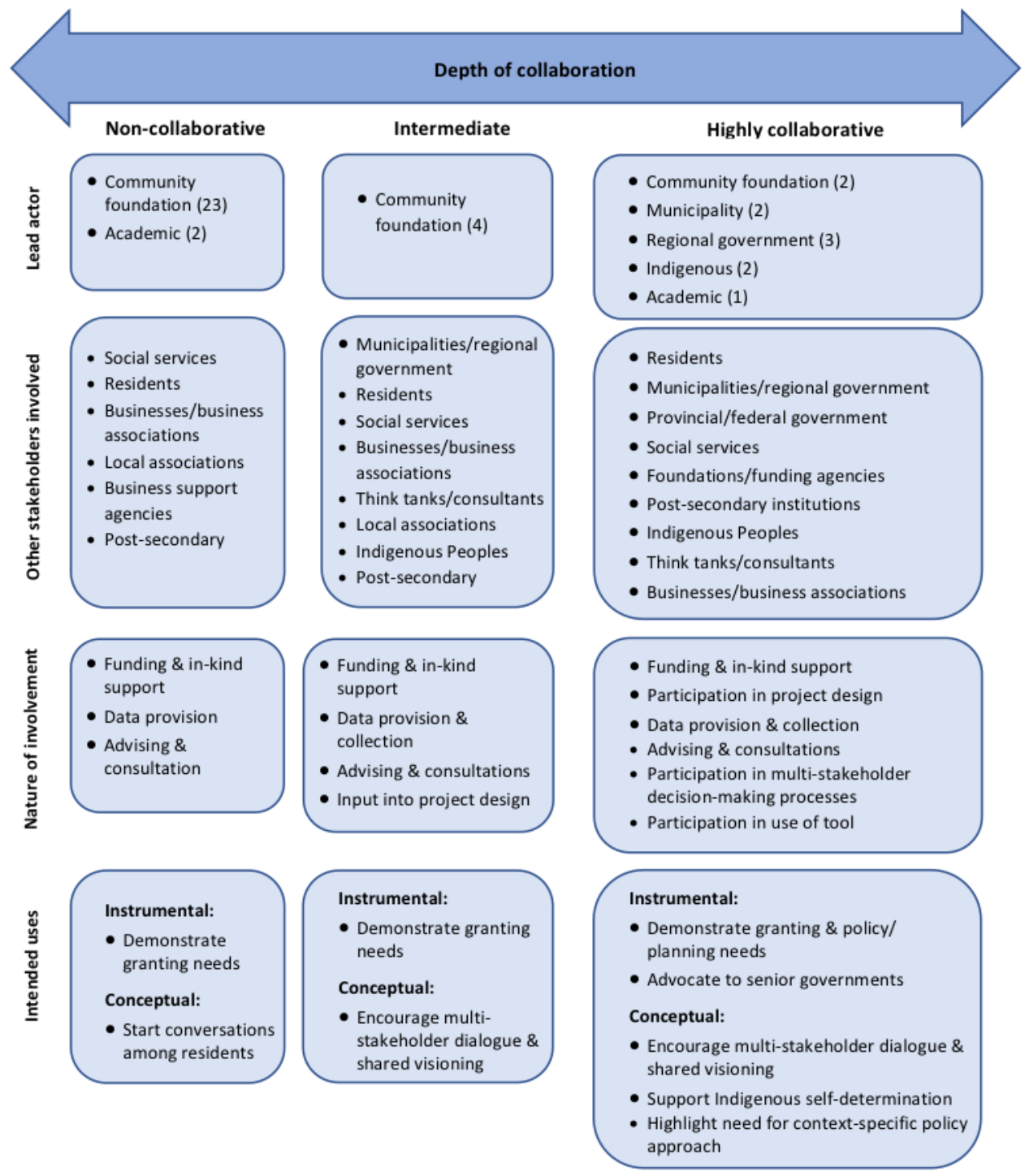

Figure 14. Typology of SI use and governance dynamics in rural Canadian SI initiatives.

\section{Discussion}

This study helps address important gaps in understanding the context-specific nature of rural SD, highlighting patterns in how current indicator-based tools represent these priorities. By examining SI initiatives from across rural and resource-based areas of Canada, we identify overarching rural SD priorities, including areas of emphasis and gaps, while addressing the need for more contextual diversity in SI research and integrative findings of individual experiences [3,6]. Furthermore, the typology above provides novel insights on how rural stakeholders use SIs in local governance and how these uses occur along a spectrum of collaborative practices $[16,53,55,61]$. Here we offer three key lessons learned, acknowledging the study's limitations, and embed its findings in current literature to suggest further SI research in rural and resource-based contexts.

\subsection{Geographic Divide in SI Initiatives and Priorities}

Rural Canada features disparate regional geographic circumstances, demography, and socio-economic forces [70]. However, our analysis found that SI initiatives tend to be carried out in communities that are close to urban centers with relatively stable populations and low levels of natural resource employment. There were 
several exceptions in highly resource-dependent and remote areas, supporting the well-established use of SI tools to strengthen resilience in communities that depend on resource sectors like forestry and mining $[30,66,108]$. However, this clustering of initiatives is not reflective of many rural Canadian realities. For example, the average amount of dependence on primary industry employment in the sample $(7.4 \%)$ is lower than across rural Canada, which was $11 \%$ in September 2020 [90], and which contributes up to $30 \%$ of labor force income in 1800 rural and remote communities [89].

Regarding the first research question, which investigated the extent to which SI tools portray a holistic $\mathrm{SD}$ vision, the community capital-based analysis reveals both divergent rural SD priorities and common interests across these geographic contexts. A high priority was placed on socio-cultural priorities like healthcare, education, and housing affordability. This finding supports that of Hallström et al. [128], who identified social sustainability as a strong feature of municipal sustainability plans in rural Canada, while reflecting many policy issues over which municipal and regional authorities have jurisdiction (e.g., housing, education). As discussed above, these socio-cultural indicators were heavily influenced by the standard framework and indicators often used by VS projects. Nonetheless, across both VS and other frameworks, we observe a common interest in sense of belonging, social inclusion, and equity, reflecting the importance of associative relations in many rural Canadian communities $[129,130]$. However, socio-cultural stocks like gender equity and the participation of residents in community life were under-emphasized. Further research should examine these areas of lower emphasis in particular rural SI initiatives, for example by examining the gender balance on community foundation boards and whether public engagement efforts sought to engage women's advocacy groups.

Rural Canadian SI initiatives also reflected concerns about economic threats and opportunities, particularly the need to sustain key sectors and anticipate changes that may affect the local labor force and exacerbate inequalities. Especially in urban-adjacent communities experiencing rapid growth, indicators emphasized concerns over development pressures like increasing tourism volumes and in-migration. These concerns underline the growing trend of amenity migration, which present rural communities with both opportunities, like increased demand for goods and services and tax revenues, and threats like gentrification and loss of local cultural identity [82,84]. As the long-term socio-economic consequences of the COVID-19 pandemic materialize, many rural communities face a possible wave of ex-urban migrants seeking to escape quarantine conditions and avail of locational flexibility in work arrangements and low-cost housing [131]. Financial resources were under-emphasized, perhaps reflecting the fact that relatively few initiatives were led by the local governments that collect taxes and allocate budgets that affect public services.

Ecological considerations ranged from the desire to preserve landscapes for recreational and aesthetic purposes to ambitious conservation and climate action priorities. In more amenity-based communities, landscape was often emphasized as a contributor to quality of life, reinforcing the role of natural assets in sense of place [132] and amenity migration strategies. We noted a particular gap in natural resource indicators, likely stemming from the low level of resource dependence across the sample; however, more remote communities (including the two Indigenous-led initiatives) placed stronger emphasis on natural resources. These findings highlight the need for consideration of the many contextual differences between urban and rural communities [133], and different kinds of rural contexts, in future research on sustainable rural development and SI tools.

\subsection{Data-Driven Approaches and Rural Capacity Gaps}

Turning to the second research question, which examined whether rural SIs support local governance, these initiatives often followed a data-driven approach with minimal stakeholder participation or attention to local context. Rehashing the long-observed tension between top-down vs. bottom-up methods in SI tools [3,12,58], most initiatives took a uniform approach, applying a standard framework and dataset to measure local SD conditions, sometimes augmented with local data sources. From a perspective of collaborative, multi-level governance $[19,20]$, this approach fails to engage a wide range of rural stakeholders, relying on instrumental exchanges like information-sharing and 
one-way knowledge dissemination rather than genuine collaboration. In contrast, several initiatives were highly collaborative, engaging multiple actors in indicator design and ongoing efforts to use them, such as Indigenous self-governance and resource management, input to regional policy development, and planning (including the two longest-running initiatives which were incorporated into municipal planning processes).

This data-driven approach was strongly related to the nature of Vital Signs, which appears to follow an expert-driven format that provides local community foundations with a pre-determined framework and set of indicators which must then be translated into local contexts (see Supplementary Materials). A number of local VS reports described this relationship, as well as CFC's website:

"CFC's role in the program, among other things, is to provide Canadian community foundations access to national data sets, which foundations typically complement with local surveys, public programming and events that mobilize community knowledge and help identify local priorities. From housing, to transit, to safety, the environment, the arts and gender equality, the reports offer invaluable insights across more than 70 indicators of quality of life at the community level" [25].

This quotation outlines a process in which the basic indicator set is organized according to CFC's framework and provided to local community foundations. In local VS reports, these priority areas (e.g., housing, safety, the environment) are rarely explained in terms of local sustainability concerns or justified with any coherent conceptual framework. Rather, they seem to be taken for granted as universal quality of life and sustainability concerns. According to a webinar released by CFC for local community foundations, this framework "... truly encompasses a $360^{\circ}$ view of the community" [134], striving for a holistic approach but in practice heavily weighting socio-cultural indicators over other priorities. In addition to this less-than-holistic framework, its strong reliance on Statistics Canada data implies that these indicators may not adequately reflect rural realities; for example, data in small communities may be suppressed for confidentiality reasons or not available at the appropriate aggregation level [135].

A related issue with VS is that it was originally designed for urban contexts, then later adapted to rural communities and regions. Holden [64] describes that:

"While Vital Signs is now led by the Community Foundations of Canada, it originated as a local project of the Toronto Community Foundation (TCF) in 2001, where the TCF was identified by other local leaders as the organization best situated to track and report on key metropolitan trends at a critical juncture for that city".

Although VS has since been adapted to rural contexts, as demonstrated here, these urban origins most likely influenced the priorities and indicators it uses.

With little available information on the rationale for the VS categories and indicators, it is difficult to disentangle the framework from the data it provides. Since CFC provides access to national-level data from Statistics Canada, which are often supplemented with locally-sourced data from agencies like school boards and health authorities, there appears to be a 'chicken and egg' problem: do the data dictate the framework, or vice versa? Given this study's reliance on secondary sources, future research on the VS program should delve into the relationship between CFC and local community foundations to examine these dynamics in-depth.

In contrast, grassroots initiatives had a more collaborative approach, engaging a wider range of stakeholders and considering a broader set of sustainability priorities, including ecological priorities like ecosystem health and economic goals like small business development. These initiatives, as well as a few VS projects, interwove standard indicators with qualitative stories, resident perceptions, and local data sources to provide a more nuanced portrait of rural sustainability.

In light of the governance challenges facing rural Canadian communities, including often-limited human resource capacity $[106,136]$, the VS approach seems to predispose local actors with less capacity to adopt its framework in a cookie-cutter manner. Designing and using SI tools impose significant 
human resource burdens [137], including expertise in data collection and analysis and familiarity with official data sources such as Statistics Canada, which are not accessible to non-experts. Given the CIW's reliance on similar data sources, and the non-collaborative nature of the two CIW projects examined in the inventory, this framework seems to place similar demands on local actors. Regarding VS projects, CFC itself suggests that community foundations hire a project manager specifically to oversee the process [134]. After CFC provides community foundations with its basic framework and indicators, any additional effort taken to contextualize these data to fit local concerns and engage stakeholders depends entirely on the capacity and intentions of the foundation. This situation puts smaller foundations (including ones serving a lower population base) at a disadvantage to those with greater staff and financial resources.

This capacity gap also relates to the study's findings regarding the geographic distribution of SI initiatives across rural Canada. As discussed above, most initiatives identified (both in the initial scan and the sample chosen for analysis) were in communities or regions enjoying stable or growing populations and located within $150 \mathrm{~km}$ of a major city. These conditions support local governments in acquiring sufficient tax revenue to undertake the work of designing grassroots SI tools, and provide community foundations with a stable donor base. The two longest-running initiatives were in municipalities that are both rapidly growing in population, close to metropolitan areas, and supported heavily by tourism activity. In contrast, more remote communities facing demographic decline or resource industry closures likely have limited capacity to sustain these efforts. These capacity gaps echo previous research on so-called lagging (vs. leading) rural regions, which experience disparate economic development challenges and potentials [138].

Considering these gaps, it appears that rural Canadian SI initiatives tend to take place in a geographic and socio-economic 'comfort zone', raising considerable equity considerations. Although urban-adjacent communities are experiencing multiple development pressures ranging from housing affordability to tourism labor crunches, the clustering of initiatives in these contexts suggests that SIs, like many other sustainability strategies, may be seen as a luxury only accessible to communities with adequate resources. In remote regions that depend on a small number of natural resource sectors, where the need to anticipate socio-ecological shocks is pressing, it is ironically prohibitive to use SIs to support holistic sustainability planning. Future research should examine how existing SI methods can be made more cost-effective for capacity-limited rural actors while foregrounding local priorities and data, surveying whether remote regions in other parts of the world have used SIs or similar tools in ways that effectively leverage existing local capacities.

One promising avenue for addressing rural capacity gaps is the growing focus on regional collaboration. Many rural Canadian regions are exploring collaborative solutions to local service-sharing, economic development, and resource management [23,24], including how roles and supports previously performed by senior governments can be fulfilled by a broader range of stakeholders. As discussed in Section 1.4, some provinces have regional governance structures to facilitate these collaborations and provide essential capacity to local actors, while others lack such regional supports [8].

This inventory of SI initiatives reinforced the importance of regional approaches to rural development, given that the vast majority of initiatives occurred at a regional scale. Interestingly, initiatives were more commonly done within some kind of administratively defined region (e.g., county, regional district, multi-county; $46.2 \%$ of initiatives) than in a region drawn by non-administrative lines $(30.8 \%)$. This trend also relates to the data-driven nature of most initiatives examined, since Statistics Canada data are already aggregated at these regional scales and can be easily retrieved. In contrast, SI initiatives carried out in regions that do not correspond with administrative boundaries may be linked to emergent forms of cross-community collaboration highlighted by previous research in self-identified regional designations like eco-regions [23,103].

Whether conducted within administrative or non-administrative regions, these findings highlight the need for SI initiatives to engage a wider range of rural actors. Although the strong role of community foundations expands the focus beyond governmental actors which have often been the 
focus of SI literature $[13,16]$, while supporting recent research on the importance of philanthropic organizations for rural sustainability in Canada [139], the data-driven approach discussed above suggests that VS may not be appropriate for foundations with limited capacity. Future research and practice should explore whether collaborative regional governance arrangements occurring in rural Canada could provide the needed capacity to initiate and sustain SI tools within such settings [24], using multi-stakeholder approaches that engage key actors like foundations, municipalities, and regional government bodies. These efforts should explore the potential for more integrative approaches that blend participatory methods like citizen science with standard datasets provided by VS or other high-level frameworks, prioritizing adaptable approaches like the Sustainability Balance to foreground locally-crafted sustainability goals while striving for effective use of existing frameworks and data [42].

\subsection{Need for Culturally Relevant Approaches to Sustainability Assessment in Indigenous Communities}

Finally, this study underlines the need for greater acknowledgment and support of Indigenous approaches to conceptualizing sustainability. Previous research on Indigenous-led SIs has highlighted that the knowledge systems of Indigenous Peoples differ from Western science-informed worldviews, including those informing the SI initiatives examined here [107-109]. For example, the mechanistic approach prevalent in many SI tools has been identified as antithetical to Maori knowledge and perspectives [62]. In the context of Canadian-Indigenous relations and implementation of the recommendations of the Truth and Reconciliation Commission [105], the examination of planning and policy instruments on Indigenous lands (including SIs) should foreground Indigenous Peoples as experts in interpreting their experiences while decolonizing these practices and supporting self-determination [140].

From this perspective, the two Indigenous initiatives examined here are not fully comparable to the other SI tools. Many indicators used in these initiatives were difficult to group into a single area of community capital, such as caribou which simultaneously represented food security, cultural continuity, ecological integrity, and spirituality. This holistic and relational worldview contrasts prevailing Western conceptions of natural resources which often reduce their value to economic terms [141], implying that it may be inappropriate to compartmentalize them into distinct indicators. Another key difference was the conceptualization of SI use in policy, which was strongly influenced by goals of Indigenous self-determination and control over resources and economic activities. For example, the Naskapi Nation initiative was intended to anticipate potential benefits and threats from nearby mining activity, while LRRCN intended to use the indicators on an ongoing basis both within Band governance and in a multi-stakeholder forestry management board. These goals are informed by a very different policy context than that of non-Indigenous local governments.

Future research and practice should acknowledge the fundamental differences between Indigenous and Western knowledge systems in relation to indicator tools and continue exploring potentials and challenges faced in seeking to assess and monitor Indigenous community well-being and sustainability. Such explorations must be driven by Indigenous priorities and understandings, including conceptions of data and measurement within these knowledge systems and consideration of potential mistrust of official data collected by non-Indigenous government sources [106].

\subsection{Limitations}

This study's primary limitation stems from its reliance on secondary data in a synthetic methodology that inherently sacrifices depth for breadth. This methodological choice prevented the detailed analysis required to understand questions like why initiatives chose the indicators they used, how those relate to salient regional development issues, or detailed local governance dynamics. These kinds of questions would better be addressed by in-depth case study research to examine these and other rural SI initiatives in the future.

The study was also limited by our purposive sampling approach, which differed from formal meta-analytical research in that we did not include all existing examples of rural Canadian SI initiatives, 
but selectively chose a sample intended to reflect the diversity of rural Canada and a variety of approaches to SI design. However, this selectivity may have inadvertently excluded relevant insights from initiatives that fell outside of the exclusion criteria (e.g., single-sector projects) or over- or under-represented certain geographic contexts or types of initiatives.

Another limitation stems from ambiguities in the definitions of rurality and remoteness, which complicated the classification of cases. Although statistical classifications like Census rural and RST exist in Canada, in practice what is considered rural differs greatly across provinces and territories based on a variety of social and geographic factors. This issue also affected the literature scan in Section 1.3, since international definitions of rurality are even more variable and we used keywords that may have inadvertently excluded rural case studies that did not use these terms. As noted in Section 2, academic publications on rural Canadian SI initiatives were scarce, requiring the search for grey literature sources. We considered how initiatives described their communities (e.g., rural, remote, Northern) while comparing them to the RST classification. Variable notions of rurality across these contexts could be examined further through comparative case studies or survey-based research.

The sample was also heavily weighted towards VS projects and the geographic context of urban-adjacent rural communities. This over-representation influenced the indicator-based analysis due to the tendency for VS projects to prioritize socio-cultural capital indicators. The strong presence of urban-adjacent contexts also weighted the indicator-based analysis towards concerns like tourism growth and amenity migration (discussed above), while development issues in more remote communities were under-represented. For example, natural resource indicators received relatively little attention, despite the continued importance of resource sectors in many rural communities.

Finally, we were limited by a language barrier that prevented a thorough examination of initiatives in Francophone areas of Canada. Although we located a provincial SI framework in Québec [117], we could not identify any local initiatives or derivations of the provincial tool. Future bilingual investigation should compare local SI tools in these areas with those examined here.

\section{Conclusions}

This article contributes to ongoing efforts to clarify the value of SI tools, expanding the focus into rural and resource-based areas and synthesizing local experiences in these contexts. The inventory presented here identifies that in rural Canada, SI initiatives have often been conducted in communities benefitting from favourable geographic and socio-economic conditions, reflecting pre-existing capacity gaps across rural contexts. This capacity issue is closely related to the prevalence of data-driven approaches that mask local contextual priorities behind standardized indicators, which are more likely when local actors have limited human resources and expertise. In contrast, a number of rural stakeholders have used these tools in more participatory ways, highlighting potential overlaps between these approaches and collaborative regional governance efforts [23,24]. These more nuanced approaches to measuring rural SD conditions often drew on local knowledge and stories, supporting recent research proposing that storytelling can be used to enrich local SI tools and mobilize rural stakeholders [142]. Demonstrated in our typology of rural SI use, this collaborative approach can engage a diverse range of stakeholders in setting a locally grounded sustainability agenda while providing essential context to interpret quantitative indicators.

Future research can compare the experiences of rural Canada to other jurisdictions, such as in the European Union where strong rural development supports under the Community-Led Local Development program could be examined to identify linkages with local SI experiences [143]. Although relatively few initiatives examined here were in highly resource-dependent areas, more in-depth investigation could compare these projects to a wider set of SI case studies in single-resource communities, both in Canada and internationally. In the context of ongoing efforts towards regional collaboration in rural Canada [8], further investigation is also needed to examine how SI tools can be used to engage a wider range of rural stakeholders. Our analysis aims to inform new pathways 
for employing indicator tools to support rural communities and regions in pursuing a holistic and ambitious sustainability vision in Canada and other contexts.

Supplementary Materials: The following are available online at http://www.mdpi.com/2071-1050/12/20/8601/s1, Table S1: Priority areas and standard indicators used by Vital Signs, Table S2: Most common indicators used in Vital Signs and non-Vital Signs initiatives, Table S3: List of Rural Canadian SI Initiatives Included in Inventory, with Initiatives Excluded During Selection, Table S4: Community capital stocks and common indicators identified across initiatives.

Author Contributions: B.L. conducted the conceptualization, methodology, formal analysis, writing, and editing, with the support of J.D. and K.V. acting as doctoral supervisors, who assisted in conceptualization, methodology, writing, review, and editing. All authors have read and agreed to the published version of the manuscript.

Funding: This research received no external funding.

Acknowledgments: The authors thank the three anonymous reviewers for their insightful comments, as well as Myron King, Environmental Policy Institute of Grenfell Campus, Memorial University for assistance with map creation.

Conflicts of Interest: The authors declare no conflict of interest.

\section{References}

1. UNCED. Agenda 21; United Nations Conference on Environment and Development: Rio de Janeiro, Brazil, 1992.

2. United Nations General Assembly. Transforming Our World: The 2030 Agenda for Sustainable Development; United Nations General Assembly: New York, NY, USA, 2015; pp. 1-5. [CrossRef]

3. Bell, S.; Morse, S. Sustainability Indicators Past and Present: What Next? Sustainability 2018, 10, 1688. [CrossRef]

4. Moreno Pires, S.; Magee, L.; Holden, M. Learning from community indicators movements: Towards a citizen-powered urban data revolution. Environ. Plan. C Polit. Space 2017, 35, 1304-1323. [CrossRef]

5. Rodrigues, M.; Franco, M. Measuring the urban sustainable development in cities through a Composite Index: The case of Portugal. Sustain. Dev. 2019, 28, 507-520. [CrossRef]

6. Ramos, T.B. Sustainability Assessment: Exploring the Frontiers and Paradigms of Indicator Approaches. Sustainability 2019, 11, 824. [CrossRef]

7. Berman, M.; Orttung, R.W. Measuring Progress toward Urban Sustainability: Do Global Measures Work for Arctic Cities? Sustainability 2020, 12, 3708. [CrossRef]

8. Vodden, K.; Douglas, D.; Markey, S.; Minnes, S.; Reimer, B. The Theory, Practice, and Potential of Regional Development: The Case of Canada; Routledge: New York, NY, USA, 2019.

9. Serageldin, I. Sustainability and the Wealth of Nations; World Bank: New York, NY, USA, 1996.

10. Roseland, M. Toward Sustainable Communities: Solutions for Citizens and Their Governments; New Society Publishers: Gabriola Island, BC, Canada, 2012.

11. Pinfield, G. The Use of Indicators in Local Sustainable Development Planning: A response to Jeb Brugmann. Local Environ. 1997, 2, 185-187. [CrossRef]

12. Holman, N. Incorporating local sustainability indicators into structures of local governance: A review of the literature. Local Environ. 2009, 14, 365-375. [CrossRef]

13. Moreno Pires, S.; Fidélis, T. Local sustainability indicators in Portugal: Assessing implementation and use in governance contexts. J. Clean. Prod. 2015, 86. [CrossRef]

14. Hák, T.; Janoušková, S.; Moldan, B.; Dahl, A.L. Closing the sustainability gap: 30 years after “Our Common Future" society lacks meaningful stories and relevant indicators to make the right decisions and build public support. Ecol. Indic. 2018, 87, 193-195. [CrossRef]

15. Brugmann, J. Is there a method in our measurement? The use of indicators in local sustainable development planning. Local Environ. 1997, 2, 59-72. [CrossRef]

16. Hezri, A.A.; Dovers, S.R. Sustainability indicators, policy and governance: Issues for ecological economics. Ecol. Econ. 2006, 60, 86-99. [CrossRef]

17. Reed, M.S.; Fraser, E.D.G.; Dougill, A.J. An adaptive learning process for developing and applying sustainability indicators with local communities. Ecol. Econ. 2006, 59, 406-418. [CrossRef]

18. Lyytimäki, J. Thermostat or thermometer? A Finnish perspective on the overloaded role of sustainability indicators in societal transition. Sustain. Dev. 2019, 2019, 817-825. [CrossRef] 
19. Ansell, C.; Gash, A. Collaborative governance in theory and practice. J. Public Adm. Res. Theory 2008, 18, 543-571. [CrossRef]

20. Bache, I.; Bartle, I.; Flinders, M. Multi-level governance. In Handbook on Theories of Governance; Ansell, C., Torfing, J., Eds.; Edward Elgar: Cheltenham, UK, 2017; pp. 486-498.

21. Florini, A.; Pauli, M. Collaborative governance for the Sustainable Development Goals. Asia Pac. Policy Stud. 2018, 5, 583-598. [CrossRef]

22. Hermans, F.L.P.; Haarmann, W.M.F.; Dagevos, J.F. Evaluation of stakeholder participation in monitoring regional sustainable development. Reg. Environ. Chang. 2011, 11, 805-815. [CrossRef]

23. Vodden, K. Governing sustainable coastal development: The promise and challenge of collaborative governance in Canadian coastal watersheds. Can. Geogr. Géographe Can. 2015, 59, 167-180. [CrossRef]

24. Gibson, R. Searching for multi-level collaborative governance. In The Theory, Practice, and Potential of Regional Development: The Case of Canada; Routledge: New York, NY, USA, 2019; pp. 79-101.

25. Community Foundations of Canada. Vital Signs. 2020. Available online: https://communityfoundations.ca/ initiatives/vital-signs/ (accessed on 18 May 2020).

26. Canadian Index of Wellbeing. How are Canadians Really Doing? The 2016 CIW Report; University of Waterloo: Waterloo, ON, Canada, 2016; pp. 1-82.

27. Peg What Is Peg? Available online: https://www.mypeg.ca/ (accessed on 17 September 2019).

28. Parkins, J.; Varghese, J.; Stedman, R. Identifying indicators of community sustainability in the Robson Valley, British Columbia. J. Ecosyst. Manag. 2004, 4, 1-19.

29. Holisko, S.; Vodden, K. Assessing the Factors Impacting the Sustainability of the Clarenville-Bonavista Rural Secretariat Region: Phase Two Final Report; Grenfell Campus, Memorial University of Newfoundand: Corner Brook, NL, Canada, 2015.

30. Uthman, R. The Role of Mining in Community Sustainability in Newfoundland and Policy Implications: A Case Study of Baie Verte; Memorial University of Newfoundland: Corner Brook, NL, Canada, 2020.

31. Winkler, R.; Oikarinen, L.; Simpson, H.; Michaelson, M.; Gonzalez, M. Boom, Bust and Beyond: Arts and Sustainability in Calumet, Michigan. Sustainability 2016, 8, 284. [CrossRef]

32. Berkes, F.; Folke, C. A systems perspective on the interrelations between natural, human-made and cultural capital. Ecol. Econ. 1992, 5, 1-8. [CrossRef]

33. Innes, J.E.; Booher, D.E. Consensus building and complex adaptive systems: A framework for evaluating collaborative planning. J. Am. Plann. Assoc. 1999, 65, 412-423. [CrossRef]

34. Pearce, D.; Atkinson, G. Capital theory and the measurement of sustainable development. Ecol. Econ. 1993, 8, 103. [CrossRef]

35. Serageldin, I.; Steer, A.D.; Cernea, M.M. (Eds.) Making Development Sustainable: From Concepts to Action; World Bank Publications: Washington, DC, USA, 1994.

36. Ekins, P.; Simon, S.; Deutsch, L.; Folke, C.; De Groot, R. A framework for the practical application of the concepts of critical natural capital and strong sustainability. Ecol. Econ. 2003, 44, 165-185. [CrossRef]

37. Mathie, A.; Cunningham, G. Who is driving development? Reflections on the transformative potential of asset-based community development. Can. J. Dev. Stud. 2005, 26, 175-186. [CrossRef]

38. Putnam, R. Bowling alone: America's declining social capital. J. Democr. 1995, 6, 65-78. [CrossRef]

39. Becker, G. Human Capital and Poverty Alleviation; Human Resources Development and Operations Policy Working Paper; World Bank: Washington, DC, USA, 1995.

40. Cochrane, P. Exploring cultural capital and its importance in sustainable development. Ecol. Econ. 2006, 57, 318-330. [CrossRef]

41. Butler, F.; Emery, M.; Fey, S.; Bregendhal, C. Community Capitals: A Tool for Evaluating Strategic Interventions and Projects; Iowa State University, North Regional Centre for Rural Development: Ames, IA, USA, 2005.

42. Knippenberg, L.; Beckers, T.; Haarmann, W.; Hermans, F.; Dagevos, J.; Overeem, I. Developing tools for the assessment of sustainable development in the province of Brabant, the Netherlands. In Sustainability Indicators-Scientific Assessment; Island Press: Washington, DC, USA, 2007; pp. 309-328.

43. Buriti, R. "Deep" or "Strong" Sustainability. In Encyclopedia of Sustainability in Higher Education; Leal Filho, W., Ed.; Springer International Publishing: Cham, Switzerland, 2019; pp. 1-10. ISBN 978-3-319-63951-2.

44. Zoeteman, K.; Mommaas, H.; Dagevos, J. Are larger cities more sustainable? Lessons from integrated sustainability monitoring in 403 Dutch municipalities. Environ. Dev. 2016, 17, 57-72. [CrossRef] 
45. Bebbington, A. Capitals and Capabilities: A Framework for Analyzing Peasant Viability, Rural Livelihoods and Poverty. World Dev. 1999, 27, 2021-2044. [CrossRef]

46. Emery, M.; Flora, C. Spiraling-Up: Mapping Community Transformation with Community Capitals Framework. Community Dev. 2006, 37, 19-35. [CrossRef]

47. Gutiérrez-Montes, I.A. Healthy Communities Equal Healthy Ecosystems? Evolution (and Breakdown) of a Participatory Ecological Research Project towards a Community Natural Resource Management Process, San Miguel Chimalapa (Mexico). Ph.D. Thesis, Iowa State University, Ames, IA, USA, 2005.

48. Lowry, J. Community Capital Tool Pilot Project in the District of Sechelt. Ph.D. Thesis, Simon Fraser University, Burnaby, BC, Canada, 2012.

49. Lowery, B. Entrepreneurs for a Sustainable Renewal: Community Capital in Greater New Orleans and the Impacts of Sustainability Entrepreneurship; Simon Fraser University: Burnaby, BC, Canada, 2013.

50. Parill, E.; White, K.; Vodden, K.; Walsh, J.; Wood, G. Regional Asset Mapping Initiative: Humber-Northern Peninsula-Southern Labrador Region; Grenfell Campus, Memorial University: Corner Brook, NL, Canada, 2014.

51. Fernando, F.N.; Goreham, G.A. A tale of two rural cities: Dynamics of community capitals during a North Dakota oil boom. Community Dev. 2018, 49, 274-291. [CrossRef]

52. Susskind, L.; Cruikshank, J.L. Breaking the Impasse: Consensual Approaches to Resolving Public Disputes; Basic Books: New York, NY, USA, 1987.

53. Peters, S.G.; Pierre, J. Comparative Governance: Rediscovering the Functional Dimensions of Governing; Cambridge University Press: Cambridge, UK, 2016.

54. Emerson, K.; Nabatchi, T.; Balogh, S. An integrative framework for collaborative governance. J. Public Adm. Res. Theory 2012, 22, 1-29. [CrossRef]

55. Arnstein, S.R. A ladder of citizen participation. J. Am. Inst. Plann. 1969, 35, 216-224. [CrossRef]

56. Himmelmann, A. Collaboration for a Change: Definitions, Decision-Making Models, Roles, and Collaboration Process Guide; Hillelmann Consulting: Minneapolis, MN, USA, 2002; p. 28.

57. Ferrarini, A.; Bodini, A.; Becchi, M. Environmental quality and sustainability in the province of Reggio Emilia (Italy): Using multi-criteria analysis to assess and compare municipal performance. J. Environ. Manage. 2001, 63, 117-131. [CrossRef]

58. Bell, S.; Morse, S. Sustainability Indicators: Measuring the Immeasurable? Earthscan: London, UK, 2008; ISBN 978-1-84407-299-6.

59. Fraser, E.D.G.; Dougill, A.J.; Mabee, W.E.; Reed, M.; McAlpine, P. Bottom up and top down: Analysis of participatory processes for sustainability indicator identification as a pathway to community empowerment and sustainable environmental management. J. Environ. Manage. 2006, 78, 114-127. [CrossRef] [PubMed]

60. Buhonovsky, L.; Jäger, J. Stakeholder integration and social learning in integrated sustainability assessment. In Long-Term Governance for Social-Ecological Change; Siebenhuner, B., Arnold, M., Eisenack, K., Jacob, K., Eds.; Routledge: New York, NY, USA, 2013; pp. 269-286.

61. Gahin, R.; Veleva, V.; Hart, M. Do Indicators Help Create Sustainable Communities? Local Environ. $2003,8$. [CrossRef]

62. Reid, J.; Rout, M. Developing sustainability indicators-The need for radical transparency. Ecol. Indic. 2020, 110, 105941. [CrossRef]

63. Loorbach, D.; Frantzeskaki, N.; Avelino, F. Sustainability Transitions Research: Transforming Science and Practice for Societal Change. Annu. Rev. Environ. Resour. 2017, 42, 599-626. [CrossRef]

64. Holden, M. Sustainability indicator systems within urban governance: Usability analysis of sustainability indicator systems as boundary objects. Ecol. Indic. 2013, 32, 89-96. [CrossRef]

65. Stepanova, N.; Gritsenko, D.; Gavrilyeva, T.; Belokur, A. Sustainable Development in Sparsely Populated Territories: Case of the Russian Arctic and Far East. Sustainability 2020, 12, 2367. [CrossRef]

66. MacKendrick, N.; Parkins, J.R. Frameworks for Assessing Community Sustainability: A Synthesis of Current Research in British Columbia; Northern Forestry Centre: Edmonton, AB, Canada, 2004; p. 26.

67. Kittinger, J.N. Participatory Fishing Community Assessments to Support Coral Reef Fisheries Comanagement. Pac. Sci. 2013, 67, 361-381. [CrossRef]

68. Jenkins, H. Corporate social responsibility and the mining industry: Conflicts and constructs. Corp. Soc. Responsib. Environ. Manag. 2004, 11, 23-34. [CrossRef]

69. Caine, K.J.; Krogman, N. Powerful or Just Plain Power-Full? A Power Analysis of Impact and Benefit Agreements in Canada's North. Organ. Environ. 2010, 23, 76-98. [CrossRef] 
70. Markey, S.; Breen, S.; Lauzon, A.; Gibson, R.; Ryser, L.; Mealy, R. State of Rural Canada 2015. Available online: http://sorc.crrf.ca (accessed on 7 June 2020).

71. Halfacree, K. Trial by space for a "radical rural": Introducing alternative localities, representations and lives. J. Rural Stud. 2007, 23, 125-141. [CrossRef]

72. Lauzon, A.; Bollman, R.D.; Ashton, B. Introduction. In State of Rural Canada. Available online: http://sorc.crrf.ca/i ntro (accessed on 7 June 2020).

73. Halseth, G.; Markey, S.; Ryser, L.; Manson, D. (Eds.) Doing Community-Based Research: Perspectives from the Field; McGill-Queen's University Press: Montreal, QC, Canada, 2016.

74. Avery, L.; Fortunato, M. Reframing rural education: Implications of the rural mystique and its absence in education policy. In Reinventing Rural: New Realities in an Urbanizing World; Lexington Books: Lanham, MD, USA, 2016; pp. 161-178.

75. Du Plessis, V.; Beshiri, R.; Bollman, R.D. Definitions of rural. Rural Small Town Can. Anal. Bull. 2001, 3, 1-17.

76. Bollman, R.D. Charts: Population levels and trends-Census Metropolitan Areas (CMAs), Census Agglomerations (CAs), Rural and Small Town (RST) Areas by province, 1966-2016. In Proceedings of the Canadian Rural Revitalization Foundation Annual Conference, Guelph, ON, Canada, 14 October 2016.

77. Statistics Canada Population and Dwelling Count Highlight Tables, 2016 Census. Available online: http: //www12.statcan.gc.ca/census-recensement/2016/dp-pd/hlt-fst/pd-pl/Table.cfm?Lang=Eng\&T=302\&SR= $1 \& \mathrm{~S}=86 \& \mathrm{O}=\mathrm{A} \& \mathrm{RPP}=9999 \& \mathrm{PR}=10$ (accessed on 28 July 2020).

78. Statistics Canada Population Size and Growth in Canada: Key Results from the 2016 Census. Available online: https://www150.statcan.gc.ca/n1/daily-quotidien/170208/dq170208a-eng.htm (accessed on 27 July 2020).

79. Christensen, J. No Home in a Homeland: Indigenous Peoples and Homeless in the Canadian North; University of British Columbia Press: Vancouver, BC, Canada, 2017.

80. Reimer, B.; Barrett, J.; Vodden, K.; Bisson, L. Rural-urban interactions and interdependence. In The Theory, Practice, and Potential of Regional Development: The Case of Canada; Routledge: New York, NY, USA, 2019; pp. 149-182.

81. Freshwater, D.; Simms, A.; Ward, J. Local Labour Markets as a New Way of Organizing Policies for Stronger Regional Economic Development in Atlantic Canada; Memorial University of Newfoundland: St. John's, NL, Canada, 2014.

82. Chipeniuk, R. Planning for Amenity Migration in Canada: Current Capacities of Interior British Columbian Mountain Communities. Mt. Res. Dev. 2004, 24, 327-335. [CrossRef]

83. Cross, J.E. Processes of Place Attachment: An Interactional Framework. Symb. Interact. 2015, 38, 493-520. [CrossRef]

84. Columbia Basin Rural Development Institute. Identifying Assets for the Knowledge Economy; Columbia Basin Rural Development Institute: Castlegar, BC, Canada, 2016.

85. Innes, H. Staples, Markets, and Cultural Change: Selected Essays of Harold Innes; McGill-Queen's University Press: Montreal, QC, Canada, 1995.

86. Breen, S.; Markey, S.; Reimer, B. Regional development in Canada: Eras and evolution. In The Theory, Practice, and Potential of Regional Development: The Case of Canada; Routledge: New York, NY, USA, 2019; pp. 12-29.

87. Statistics Canada Natural Resource Indicators, First Quarter 2019. Available online: https://www150.statcan .gc.ca/n1/daily-quotidien/190626/dq190626a-eng.htm (accessed on 10 June 2020).

88. Government of Canada. 10 Key Facts on Canada's Natural Resources; Natural Resources Canada: Ottawa, ON, Canada, 2019.

89. Vodden, K.; Cunsolo Willox, A.; Harper, S.L.; Kipp, A.; King, N.; Manners, S.; Eddy, B.; Breen, S.; Hextall, S.; Rethoret, L. Rural and remote communities. In Canada in a Changing Climate: National Issues; Government of Canada: Ottawa, ON, Canada, 2021.

90. Bollman, R. Employment in Rural and Small Town Areas in the Months BCE (before Covid Era or before Coma Economy) and in the Months CE (Covid era or Coma Economy): Selected charts up to September, 2020; Rural Development Institute: Brandon, MB, Canada, 2020.

91. Irshad, H. Attracting and Retaining People to Rural Alberta: A List of Resources and Literature Review; Government of Alberta, Rural Development Division: Edmonton, AB, Canada, 2013.

92. Johnson, K. Rural Demographic Change in the New Century: Slower Growth, Increased Diversity; Carsey Institute: Durham, NH, USA, 2012. 
93. Statistics Canada Proportion of the Population Living in Rural Areas, Canada, 1851 to 2011. Available online: https: //www12.statcan.gc.ca/census-recensement/2011/as-sa/98-310-x/2011003/fig/fig3_2-1-eng.cfm (accessed on 17 January 2020).

94. Statistics Canada Population Counts, for Canada, Provinces and Territories, Census Divisions, Population Centre Size Groups and Rural Areas, 2016 Census-100\% Data. Available online: https://www12.statcan.gc.ca/census-rec ensement/2016/dp-pd/hlt-fst/pd-pl/Table.cfm?Lang=Eng\&T=703\&S=87\&O=A (accessed on 28 May 2020).

95. Statistics Canada Census Profile, 2016 Census. Available online: https:/www12.statcan.gc.ca/census-recense ment/2016/dp-pd/prof/details/page.cfm?Lang=E\&Geo1=PR\&Code1=01\&Geo2=\&Code2=\&SearchText= Canada\&SearchType $=$ Begins $\&$ SearchPR=01\&B1=All\&TABID=1\&type $=0$ (accessed on 18 May 2020).

96. Government of NL. Regional Economic Development. Available online: https://www.gov.nl.ca/tcii/regionaleconomic-development-division/ (accessed on 18 May 2020).

97. Hall, H.; Vodden, K.; Greenwood, R. From Dysfunctional to Destitute: The Governance of Regional Economic Development in Newfoundland and Labrador. Int. Plan. Stud. 2016, 1-19. [CrossRef]

98. Government of Ontario. Ministry of Agriculture, Food, \& Rural Affairs. Available online: http://www.omaf ra.gov.on.ca/english/ (accessed on 18 May 2020).

99. Wilson, B. Feds abolish Rural Secretariat 2013. The Western Producer. Available online: https://www.produc er.com/daily/feds-abolish-rural-secretariat/ (accessed on 19 May 2020).

100. Government of Canada Rural Economic Development. Available online: https://www.infrastructure.gc.ca/r ural/index-eng.html (accessed on 18 May 2020).

101. Vodden, K.; Lane, R.; Pollett, C. Seeking Sustainability through Self-Assessment and Regional Cooperation in Newfoundland and Labrador. In Sustainability Planning and Collaboration in Rural Canada: Taking the Next Steps; Hallstrom, L., Beckie, M., Hvenegaard, G., Mundel, K., Eds.; University of Alberta Press: Edmonton, AB, Canada, 2016; pp. 321-346.

102. Breen, S.; Markey, S. Unintentional Influence: Exploring the Relationship between Rural Regional Development and Drinking Water Systems in Rural British Columbia, Canada. J. Rural Community Dev. 2015, 10, 51-77.

103. Chireh, V. Exploring a Regional Approach in Drinking Water Management in the Strait of Belle Isle, Newfoundland and Labrador. Master's Thesis, Memorial University of Newfoundland, Corner Brook, NL, Canada, 2018.

104. Gibson, R. Collaborative Governance in Rural Regions: An Examination of Ireland and Newfoundland and Labrador. Ph.D. Thesis, Memorial University of Newfoundland, St. John's, NL, Canada, 2014.

105. Government of Canada. Delivering on Truth and Reconciliation Commission Calls to Action. Available online: https://www.rcaanc-cirnac.gc.ca/eng/1524494530110/1557511412801 (accessed on 3 March 2020).

106. Penner, S.; Baribeau, A.; Neeposh, I.; Longboat, S. Indigenous Peoples. In State of Rural Canada 3: Bridging Rural Data Gaps. Available online: http://sorc.crrf.ca (accessed on 7 June 2020).

107. Smith, P.; Symington, E.; Allen, S. First Nations' criteria and indicators of sustainable forest management: A review. In Planning Co-Existence: Aboriginal Issues in Forest and Land Use Planning, Research and Insights from the Aboriginal Program of the Sustainable Forest Management Network; CCI Press: Edmonton, AB, Canada, 2010; pp. 225-264.

108. Klinck, R.; Bradshaw, B.; Sandy, R.; Nabinacaboo, S.; Mameanskum, M.; Guanish, M.; Einish, P.; Guanish, G.; Pien, S. Enabling Community Well-being Self-Monitoring in the Context of Mining: The Naskapi Nation of Kawawachikamach. Engaged Sch. J. 2015, 1, 114-130. [CrossRef]

109. Natcher, D.C.; Hickey, C.G. Putting the Community Back Into Community-Based Resource Management: A Criteria and Indicators Approach to Sustainability. Hum. Organ. 2002, 61, 350-363. [CrossRef]

110. Saskatchewan Index of Well-being. Saskatchewan Index of Well-being. Available online: http://www.saskwe llbeing.ca/ (accessed on 17 September 2019).

111. Government of Canada. A Proposed New Impact Assessment System. Available online: https://www.canada.ca/en/s ervices/environment/conservation/assessments/environmental-reviews/environmental-assessment-processes.html (accessed on 6 October 2020).

112. Wilson, J.; Tyedmers, P. Rethinking What Counts. Perspectives on Wellbeing and Genuine Progress Indicator Metrics from a Canadian Viewpoint. Sustainability 2013, 5, 187-202. [CrossRef]

113. May, D.; Hollett, A. The system of Community Accounts: An application to Newfoundland and Labrador. In Proceedings of the Paper presented for the 30th General Conference of the International Association for 
Research in Income and Wealth, Portoroz, Slovenia, 24 August 2008; Organization for Economic Cooperation and Development: Portoroz, Slovenia, 2008.

114. Schreiber, R.; Crooks, D.; Stern, P. Qualitative meta-analysis. In Completing a Qualitative Project: Details and Dialogue; Sage: New York, NY, USA, 1997; pp. 311-326.

115. Walsh, D.; Downe, S. Meta-synthesis method for qualitative research: A literature review. J. Adv. Nurs. 2005, 50, 204-211. [CrossRef] [PubMed]

116. Newig, J.; Fritsch, O. The Case Survey Method and Applications in Political Science. In Proceedings of the APSA 2009 meeting, Toronto, ON, Canada, 3-6 September 2009; American Political Science Association: Toronto, ON, Canada, 2009.

117. Government of Québec. Recueil des Indicateurs de Développement Durable. Available online: https: //www.stat.gouv.qc.ca/statistiques/developpement-durable/indicateurs/recueil-indicateurs-dd.pdf (accessed on 28 May 2020).

118. Stan, L. Stan Content analysis. In Encyclopedia of Case Study Research; Sage Publications: Thousand Oaks, CA, USA, 2010.

119. Philanthropic Foundations of Canada Canadian Foundation Facts. Available online: https://pfc.ca/resources /canadian-foundation-facts/ (accessed on 11 August 2020).

120. Community Foundation of the North Okanagan. The North Okanagan's Vital Signs: 2017; Community Foundation of the North Okanagan: Vernon, BC, Canada, 2017.

121. Community Foundation of Southeastern Alberta. Medicine Hat's Vital Signs: 2017; Community Foundation of Southeastern Alberta: Medicine Hat, AB, Canada, 2017.

122. Brandon Area Community Foundation. Brandon Area Vital Signs: 2019; Brandon Area Community Foundation: Brandon, MB, Canada, 2019.

123. Biosphere Institute of the Bow Valley. Canmore Community Monitoring Program 2018 Final Report; Biosphere Institute of the Bow Valley: Canmore, AB, Canada, 2018.

124. Community Foundation of Nova Scotia. Strait Region's Vital Signs: 2019; Community Foundation of Nova Scotia: Halifax, NS, Canada, 2019.

125. Columbia Valley Community Foundation. Columbia Valley's Vital Signs: 2018; Columbia Valley Community Foundation: Invermere, BC, Canada, 2016.

126. Community Foundation of Nova Scotia. Lunenburg County's Vital Signs: 2013; Community Foundation of Nova Scotia: Halifax, NS, Canada, 2013.

127. Headwaters Communities in Action. Community Priorities in Headwaters, 2016: Increasing Community Well-Being and Resilience; Headwaters Communities in Action: Mono, ON, Canada, 2016.

128. Hallström, L.K.; Hvenegaard, G.T.; Stonechild, J.L.; Dipa, N.J. Rural sustainability plans in Canada: An analysis of structure, content and influence. J. Rural Stud. 2017, 56, 132-142. [CrossRef]

129. Reimer, B. A Rural Perspective on Linkages among Communities; Infrastructure Canada: Ottawa, ON, Canada, 2005.

130. Markey, S.; Breen, S.; Vodden, K.; Daniels, J. Identity and commitment to place: How regions "become" in rural Canada. In The Theory, Practice, and Potential of Regional Development: The Case of Canada; Routledge: New York, NY, USA, 2019; pp. 102-122.

131. Hall, H.; Gibson, R.; Markey, S.; Weedon, A. Supporting Rural Economic Recovery and Resilience after COVID-19; Rural Insight Series: COVID-19. Available online: http://sorc.crrf.ca (accessed on 19 May 2020).

132. Beckley, T.M.; Stedman, R.C.; Wallace, S.M.; Ambard, M. Snapshots of What Matters Most: Using Resident-Employed Photography to Articulate Attachment to Place. Soc. Nat. Resour. 2007, 20, 913-929. [CrossRef]

133. Markey, S.; Connelly, S.; Roseland, M. 'Back of the Envelope': Pragmatic Planning for Sustainable Rural Community Development. Plan. Pract. Res. 2010, 25, 1-23. [CrossRef]

134. Community Foundations of Canada. Taking the Pulse of Your Community: An Introduction to Vital Signs for Community Foundations; Community Foundations of Canada: Ottawa, ON, Canada, 2018.

135. Main, H.; Breen, S.; Collins, D.; Gaspard, V.; Lowery, B.; Minnes, S.; Reimer, B. State of Rural Canada III: Bridging Rural Data Gaps. Available online: http://sorc.crrf.ca (accessed on 7 June 2020).

136. Beckley, T.M.; Martz, D.; Nadeau, S.; Wall, E.; Reimer, B. Multiple Capacities, Multiple Outcomes: Delving Deeper into the Meaning of Community Capacity. J. Rural Community Dev. 2008, 3, 56-75.

137. Moreno Pires, S. Sustainability Indicators and Local Governance in Portugal. Ph.D. Thesis, The University of Aveiro, Aveiro, Portugal, 2011. 
138. Bollman, R.; Terluin, I.; Post, J.; Godeschalk, F. Comparative analysis of leading and lagging rural regions in OECD countries in the 1980s and 1990s. In Proceedings of the North American Regional Science Society 2004 Annual Meeting, Seattle, WA, USA, 11-13 November 2004.

139. Levett, K.; Markey, S.; Gibson, R.; Vodden, K.; Furst, B. New Foundations: Mobilizing the Potential of Place-Based Philanthropy for Rural Planning and Development. Available online: http://cip-icu.ca/Resourc es/Plan-Canada\# (accessed on 2 September 2020).

140. Hudson, A.; Vodden, K. Decolonizing Pathways to Sustainability: Lessons Learned from Three Inuit Communities in NunatuKavut, Canada. Sustainability 2020, 12, 4419. [CrossRef]

141. Tagalik, S. Inuit knowledge systems, elders, and determinants of health: Harmony, balance, and the role of holistic thinking. In Determinants of Indigenous Peoples' Health: Beyond the Social; CSP Books: Toronto, ON, Canada, 2018; pp. 93-101.

142. Lowery, B.; Dagevos, J.; Chuenpagdee, R.; Vodden, K. Storytelling for sustainable development in rural communities: An alternative approach. Sustain. Dev. 2020. [CrossRef]

143. The European Commission. LEADER/CLLD. Available online: https://enrd.ec.europa.eu/leader-clld_en (accessed on 28 January 2020).

Publisher's Note: MDPI stays neutral with regard to jurisdictional claims in published maps and institutional affiliations.

(C) 2020 by the authors. Licensee MDPI, Basel, Switzerland. This article is an open access article distributed under the terms and conditions of the Creative Commons Attribution (CC BY) license (http://creativecommons.org/licenses/by/4.0/). 